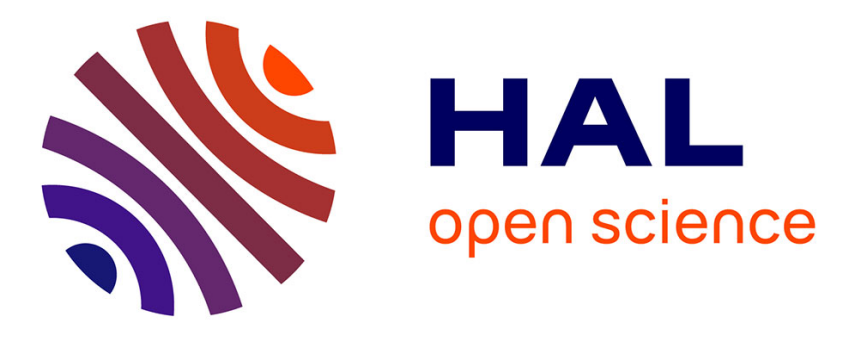

\title{
Self-Assembly of Amphiphilic Biotransesterified $\beta$-Cyclodextrins: Supramolecular Structure of Nanoparticles and Surface Properties
}

\author{
Jean-Luc Putaux, Christine Lancelon-Pin, François-Xavier Legrand, Marion \\ Pastrello, Luc Choisnard, Annabelle Gèze, Cyrille Rochas, Denis \\ Wouessidjewe
}

\section{To cite this version:}

Jean-Luc Putaux, Christine Lancelon-Pin, François-Xavier Legrand, Marion Pastrello, Luc Choisnard, et al.. Self-Assembly of Amphiphilic Biotransesterified $\beta$-Cyclodextrins: Supramolecular Structure of Nanoparticles and Surface Properties. Langmuir, 2017, 33 (32), pp.7917-7928. 10.1021/acs.langmuir.7b01136 . hal-02106206

\section{HAL Id: hal-02106206 https://hal.science/hal-02106206}

Submitted on 10 Sep 2021

HAL is a multi-disciplinary open access archive for the deposit and dissemination of scientific research documents, whether they are published or not. The documents may come from teaching and research institutions in France or abroad, or from public or private research centers.
L'archive ouverte pluridisciplinaire HAL, est destinée au dépôt et à la diffusion de documents scientifiques de niveau recherche, publiés ou non, émanant des établissements d'enseignement et de recherche français ou étrangers, des laboratoires publics ou privés. 


\section{Self-Assembly of Amphiphilic Biotransesterified $\beta$-Cyclodextrins: Supramolecular Structure of Nanoparticles and Surface Properties}

Jean-Luc Putaux, ${ }^{1,2, *}$ Christine Lancelon-Pin, ${ }^{1,2,3,4}$ François-Xavier Legrand, ${ }^{5}$

Marion Pastrello, ${ }^{1,2}$ Luc Choisnard, ${ }^{3,4}$ Annabelle Gèze, ${ }^{3,4}$ Cyrille Rochas, ${ }^{1,2}$

Denis Wouessidjewe $e^{3,4}$

${ }^{1}$ Univ. Grenoble Alpes, Centre de Recherches sur les Macromolécules Végétales (CERMAV), F-38000 Grenoble, France

${ }^{2}$ CNRS, CERMAV, F-38000 Grenoble, France

${ }^{3}$ Univ. Grenoble Alpes, Département de Pharmacochimie Moléculaire (DPM), F-38000 Grenoble, France

${ }^{4}$ CNRS, DPM, F-38000 Grenoble, France

${ }^{5}$ Institut Galien Paris-Sud, CNRS UMR 8612, Univ. Paris-Sud, Univ. Paris-Saclay, 5 Rue Jean-Baptiste Clément, F-92296 Châtenay-Malabry, France

* corresponding author: jean-luc.putaux@cermav.cnrs.fr

Published in: Langmuir 33 (2017), 7917-7928

DOI: 10.1021/acs.langmuir.7b01136

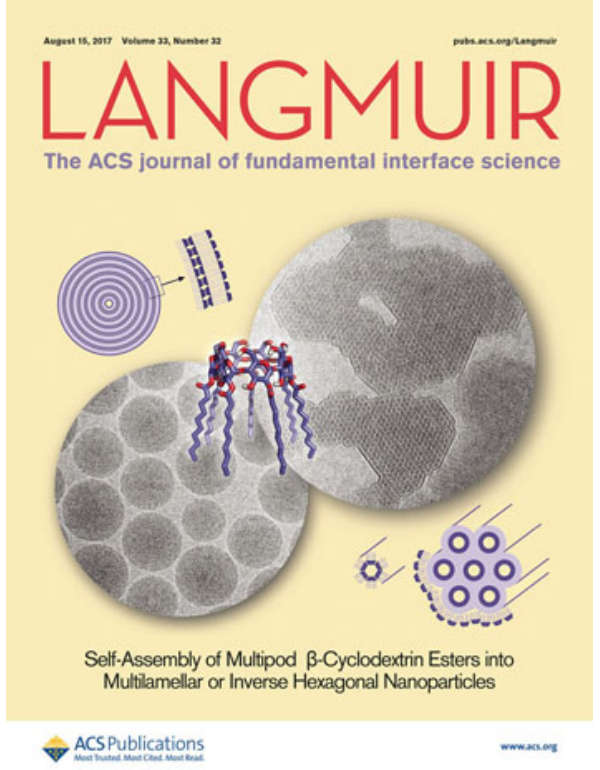




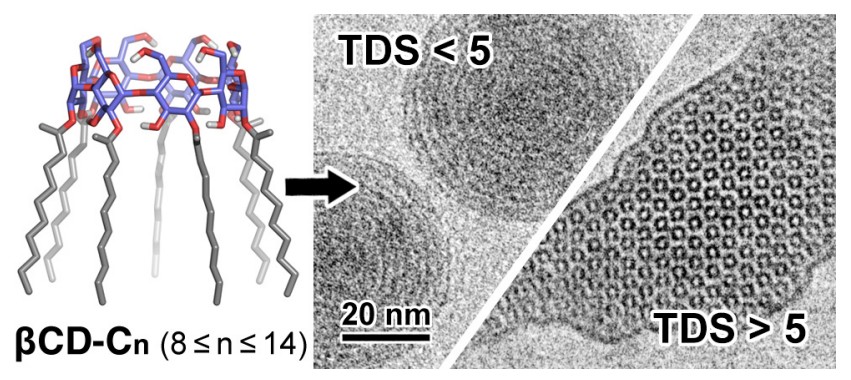

\begin{abstract}
A series of $\beta$-cyclodextrin $(\beta C D)$ amphiphilic derivatives with varying degree of substitution was prepared by acylating $\beta C D$ s on their secondary face using thermolysin to catalyze the transesterification. After dissolution in acetone, the $\beta C D-C_{n}$ derivatives $(n=8,10,12,14)$ were nanoprecipitated in water where they self-organized into structured particles which were characterized using cryo-transmission electron microscopy (cryo-TEM) images and smallangle X-ray scattering (SAXS) data. Two types of morphologies and ultrastructures were observed depending on the total degree of substitution (TDS) of the parent derivative. The molecules with TDS $<5$ formed nanospheres with a multilamellar organization whereas those with TDS $>5$ self-assembled into barrel-like $(n=8,10,12)$ or more tortuous $(n=14)$ particles with a columnar inverse hexagonal structure. In particular, facetted $\beta C D-C_{14}$ particles $(\mathrm{TDS}=7)$ appeared to be composed of several domains with different orientations and separated by sharp interfaces. Ultrastructural models were proposed based upon cryo-TEM images and the analysis of the contrast distribution in different projections of the lattice. Complementary compression isotherms experiments carried out at the air-water interface also suggested that differences in molecular conformation of the series of derivatives existed depending on whether TDS was lower of higher than 5.
\end{abstract}

KEYWORDS: amphiphilic cyclodextrin, $\beta$-cyclodextrin ester, self-assembly, nanoparticle, hexosome, cryo-TEM, SAXS, compression isotherm 


\section{INTRODUCTION}

Nanomedicine refers to a branch of medicine that takes advantage of nanotechnology platforms and allows scientists and physicians to design smart nanoscale carriers, generally in a size range of 20-150 nm, based upon liposomes, polymer and lipid nanoparticles, protein nanospheres, dendrimers, micelles, etc., capable of interaction with living cells. These nanocarriers loaded with therapeutic or diagnostic molecules circumvent various mechanical and physiological barriers leading to optimal drug targeting and diagnostic analysis. ${ }^{1-4}$ Currently, a number of nanomedical applications have been developed and the pharmaceutical market accounts for about 20 launched products. ${ }^{5}$ It is asserted that the treatment of infectious diseases and cancers have substantially improved on tolerance due to nanodrug formulations. ${ }^{5-7}$ In this context of tremendous impact of nanotechnology on medical sciences, government programs in Europe and USA as well as private industry and academic research have been initiated in order to respond to the increasing demand of physicians and patients regarding nanomedicine.

So far, many multifunctional nanocarriers have been developed, based upon the supramolecular self-assembling of different molecules, the most representative being lipids (phospholipids and cholesterol) which are the main constituents of liposomes already used in launched products such as Ambisome ${ }^{\circledR}$, Doxil ${ }^{\circledR}$ and Myocet ${ }^{\circledR}$. Although biodegradable polymers such as poly(lactid acid) (PLA), poly(lactic co-glycolic acid (PLGA), poly( $\varepsilon$-caprolactone) (PCL) are intensively studied, ${ }^{8}$ the corresponding products have not reached the market yet. Human albumin is used in nanospheres loaded with paclitaxel (Abraxane ${ }^{\circledR}$ ) that have been approved by the U.S. Food and Drug Administration for intravenous injection.

During the past decades, cyclodextrins (CDs) have also been considered as building block to construct miscellaneous nanoparticles. ${ }^{9-11}$ Cyclodextrins are macrocyclic oligosaccharides made of glycosyl units linked by $\alpha(1 \rightarrow 4)$ glycosidic bonds. Among them, $\alpha, \beta$ and $\gamma \mathrm{CDs}$ comprising 6, 7 and 8 glucosyl units, respectively, are obtained by enzymatic conversion of starch by the cyclodextrin glycosyl transferase. ${ }^{12} \mathrm{CDs}$ and their hydrophilic derivatives form inclusion compounds with a variety of hydrophobic molecules by entrapping them in their apolar cavity, resulting in higher drug solubility and stability, enhanced drug absorption, and improving drug permeability across biological barriers. ${ }^{13}$ Some inclusion complex products, intended for oral, parenteral, nasal, rectal and ocular routes have reached the market, thus attesting of the biocompatibility and the safety of these CDs and their hydrophilic derivatives. 
Taking advantage of the exposed primary and secondary hydroxyl alcohols of the glucosyl units, CDs can be chemically modified to prepare new functionalized derivatives. In particular, amphiphilic CDs have attracted a significant interest and several review articles can be found that survey the state of art and future prospects of various nanocarriers. ${ }^{10,11,14-17}$ Amphiphilic CDs are prepared by grafting hydrophobic substituents on the primary or secondary face, or both. They can be designed to respond to external stimuli, ${ }^{18}$ insert themselves in bilayer membranes ${ }^{19}$ or form aggregates able to encapsulate and carry active compounds and drugs to specific targets. ${ }^{20,21}$ They can self-organize into a large range of supramolecular assemblies depending on the chemical nature of the grafted chains, the location of the substitution and the degree of substitution. ${ }^{14,22-28}$

A specific type of amphiphilic CDs was prepared by grafting fatty acids with different chain lengths on the hydroxyl groups of the CD secondary face, either by following a chemical pathway ${ }^{29-31}$ or using thermolysin as a biocatalyzer of transesterification by a vinyl fatty ester donor. ${ }^{32,33}$ The resulting derivatives have been shown to self-organize via a nanoprecipitation procedure into nanospheres or nanoreservoirs systems, depending in the formulation, ${ }^{31,34-36}$ and were studied for their ability to encapsulate and release drugs. ${ }^{26,37-39}$ In particular, nanocarriers loaded with artemisinin, a well-known antimalarial drug, were investigated. The surface-decorated (with PEG 1500 or $2000 \mathrm{Da}$, and polysorbate 80) nanospheres and nanoreservoirs were evaluated as potential long-circulating nanocarriers for vascular administration. ${ }^{36}$ In particular, the behavior of nanocarriers based upon $\gamma$ CDs grafted with $\mathrm{C}_{10}$ alkyl chains toward the immune system (complement activation and macrophage uptake) was studied in vitro. The biodistribution, hemolytic and stealth properties of the nanosystems in mice were evaluated as well. ${ }^{40}$

In a previous report, we have shown that the morphology of the nanoparticles prepared from a series of derivatives based upon $\beta C D$ s grafted with $C_{n}$ alkyl chains $\left(\beta C D-C_{n}\right.$ with $n=6,8$, 10, 12 and 14) depended on the length of the grafted alkyl chains. ${ }^{31}$ The images recorded by cryo-electron transmission microscopy (cryo-TEM) also suggested that different supramolecular structures existed. In particular, spherical particles made of $\beta C D-C_{10}$ molecules clearly exhibited a multilamellar organization that was described as a concentric packing of bilayers. ${ }^{33}$ In addition, small-angle X-ray scattering (SAXS) data collected from a series of $\beta C D-C_{10}$ nanosystems suggested that a hexagonal supramolecular organization could also occur depending on the degree of substitution of the parent derivative, but this structure was not described with precision. ${ }^{41}$ 
The present paper summarizes the results of a more detailed ultrastructural study of the colloidal nanoparticles prepared from a series of $\beta C D-C_{n}$ derivatives $(n=8,10,12$ and 14). The influence of the length of the alkyl moieties and the degree of substitution of the derivatives on the morphology and supramolecular structure of the resulting nanoparticles was investigated using a combination of cryo-TEM imaging and SAXS analysis. Tentative models of the different organizations down to the molecular level are proposed and discussed. Complementary information on the molecular conformation of the derivatives and their selfassembling behavior at air-water interfaces were obtained from surface pressure measurements using the Langmuir film method.

\section{EXPERIMENTAL SECTION}

\subsection{Materials}

$\beta C D\left(\right.$ Kleptose $\left.^{\circledR}\right)$ was provided by Roquette Frères (Lestrem, France). Thermolysin (EC 3.4.24.27), a type X protease isolated from Bacillus thermoproteolyticus rokko, anhydrous DMSO (99 \%), vinyl octanoate, vinyl decanoate, vinyl dodecanoate and vinyl myristate (95\%) were purchased from Sigma-Aldrich (l'Isle d'Abeau Chesnes, France). Acetone (Acros Organics, analytical grade) was from Fischer Scientific (Illkirch, France). The nanoparticles were prepared in ultrapure water (Elga Purelab).

\subsection{Synthesis and Characterization of the $\beta C D-C_{n}$ Derivatives}

The $\beta C D$ fatty esters were biosynthesized according to the procedure previously described by Choisnard et al, ${ }^{33,35}$ that involves thermolysin as biocatalyzer and vinyl esters $\left(\mathrm{C}_{\mathrm{n}}\right)$ as acyl donors. The alkyl chains were grafted mostly on the secondary face of the $\beta C D$ at the $C 2$ position of the glucosyl units. The $3 \mathrm{D}$ representation of a $\beta C D-\mathrm{C}_{10}$ derivative is given as an example in Figure 1. The resulting $\beta C D$ fatty esters were analyzed by matrix-assisted laser desorption/ionization mass spectroscopy (MALDI-MS). From the MALDI-MS results and according to a validated analytical method, ${ }^{41}$ the products were characterized by their average molar weight $\overline{M_{n}}$ and total degree of substitution (TDS), as defined by Challa et al. ${ }^{42}$ The formula used by Choisnard et $a l^{41}$ to calculate TDS is provided as Supporting Information. The values for each derivative are summarized in Table 1. 


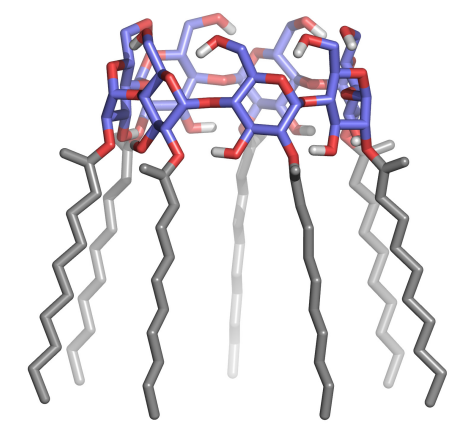

Figure 1. Schematic model of a transesterified $\beta C D-C_{10}$ derivative (TDS $=7$ ). The grafted alkyl chains are drawn in gray. The hydrogen atoms have been omitted for clarity.

Table 1. Molecular characteristics of the synthesized $\beta C D-C_{n}$ derivatives: average molar weight $\overline{M_{n}}$ and total degree of substitution (TDS, as defined by Challa et alt2 and calculated according to the method of Choisnard et $a l^{41}$ - see Supporting Information).

\begin{tabular}{c|cccccccc}
\hline$n_{\mathrm{C}}$ & 8 & 8 & 10 & 10 & 12 & 12 & 14 & 14 \\
\hline$\overline{M_{n}}\left(\mathrm{~g} \mathrm{~mol}^{-1}\right)$ & 1649.1 & 1985.1 & 1803.5 & 2266.5 & 1837.9 & 2173.5 & 1632.6 & 2599.5 \\
TDS & 4.1 & 6.7 & 4.3 & 7.3 & 3.9 & 5.7 & 2.6 & 7.0 \\
\hline
\end{tabular}

\subsection{Nanoparticle Preparation}

$\beta C D-C_{n}$ nanoparticles were prepared using the solvent displacement method. ${ }^{22} 10 \mathrm{mg}$ of $\beta C D-C_{n}$ derivatives were dissolved in acetone $(10 \mathrm{~mL})$ to reach a concentration of $1 \mathrm{mg} \mathrm{mL}^{-1}$. The solutions were kept at $25{ }^{\circ} \mathrm{C}$ in a double envelope set-up and poured into an equal volume of distilled water under magnetic stirring $(500 \mathrm{rpm})$. The nanoparticles spontaneously formed and the organic solvent was removed under reduced pressure. The suspensions were concentrated at $40{ }^{\circ} \mathrm{C}$ under vacuum $\left(1.5 \mathrm{mg} \mathrm{mL}^{-1}\right)$, filtered through $0.8 \mu \mathrm{m}$ filters and kept in vials at room temperature for TEM imaging. The samples were further concentrated by centrifugation (9600 $\mathrm{g}$ ) to about $5 \mathrm{mg} \mathrm{mL}^{-1}$ for cryo-TEM observation and X-ray scattering analyses.

\subsection{Cryo-transmission Electron Microscopy}

Cryo-TEM specimens were prepared by vitrifying thin liquid films of $5 \mathrm{mg} \mathrm{mL}^{-1}$ nanoparticle suspensions formed on Pelco Netmesh lacy carbon films at room temperature into liquefied ethane, using a Leica EM-GP workstation. Once mounted in a Gatan 626 cryoholder precooled with liquid nitrogen, the specimens were observed at low temperature $\left(-180{ }^{\circ} \mathrm{C}\right)$, under low dose illumination, using a Philips CM200 'Cryo' microscope operating at $80 \mathrm{kV}$. The images were recorded on Kodak SO163 films. Power spectra of selected regions of the images were calculated using the ImageJ software. 


\subsection{Small-Angle X-Ray Scattering}

The suspensions were concentrated by centrifugation and the pellets were poured into glass capillaries (1.0 mm outer diameter). The capillaries were flame-sealed and X-rayed overnight in vacuum using a Philips PW383 generator operating at $30 \mathrm{kV}$ and $20 \mathrm{~mA}$ (Ni-filtered CuKa radiation, $\lambda=0.1542 \mathrm{~nm}$ ). Two-dimensional scattering patterns were recorded on Fujifilm imaging plates read with a Fujifilm BAS-1800II bio-imaging analyzer. SAXS analyses were carried out as well on the BM02 (D2AM) beamline at the European Synchrotron Radiation Facility (Grenoble, France). Series of glass capillaries (1.5 mm outer diameter) and glass tubes (3.0 mm outer diameter) were filled with $5 \mathrm{mg} \mathrm{mL}^{-1}$ nanoparticle suspensions and attached to an automatic heating sample changer. Scattering patterns were recorded at room temperature, during 20-100 s, at an energy of 8 or $16 \mathrm{keV}(\lambda=0.1549$ or $0.0775 \mathrm{~nm}$, respectively) with a CCD detector placed at a distance of 20-25 cm. SAXS profiles were calculated by radially averaging the two-dimensional patterns and the profile of a sample containing only water was subtracted. In the case of hexagonal structures, the diffraction peaks were fitted with Gaussian functions and the unit cell parameter $a_{\text {hex }}$ was calculated using a least-squares regression. The SAXS patterns were calibrated using a silver behenate standard.

\subsection{Surface Pressure Measurements}

The surface pressure-surface area isotherms $(\pi-A)$ for amphiphilic cyclodextrin films were recorded using a KSV Nima Large Langmuir trough (Biolin Scientific) equipped with two Delrin barriers moving symmetrically and enclosed in a plexiglas cabinet. Before each experiment, the trough and barriers were thoroughly cleaned with chloroform and ethanol respectively and then with $n$-heptane and, finally, a paper Wilhelmy plate (Biolin Scientific) was attached to the pressure sensor. The trough was then filled with ultrapure water (18.2 $\mathrm{M} \Omega \mathrm{cm}$ ) and thermostated at $24.0 \pm 0.2^{\circ} \mathrm{C}$ with a CD200F Bath Circulator (Julabo). The water surface was cleaned until the surface pressure reading was zero. The amphiphilic cyclodextrin was solubilized in chloroform/methanol (6:4), spread on the water surface $\left(775.75 \mathrm{~cm}^{2}\right)$ with a Microman micropipette (Gilson), and left for $15 \mathrm{~min}$ to allow the solvent to evaporate. The barriers were slowly moved to compress the film at a rate of $18.6 \mathrm{~mm} \mathrm{~min}^{-1}$ while measuring the surface pressure as a function of the area per molecule until the film leaked. This isotherm was repeated three times to ensure reproducibility and the results reported are means of four measurements. The surface compressional modulus $C_{s}{ }^{-1}$ was calculated from the $\pi-A$ isotherm using the equation $C_{s}^{-1}=-A \times d \pi / d A$. 

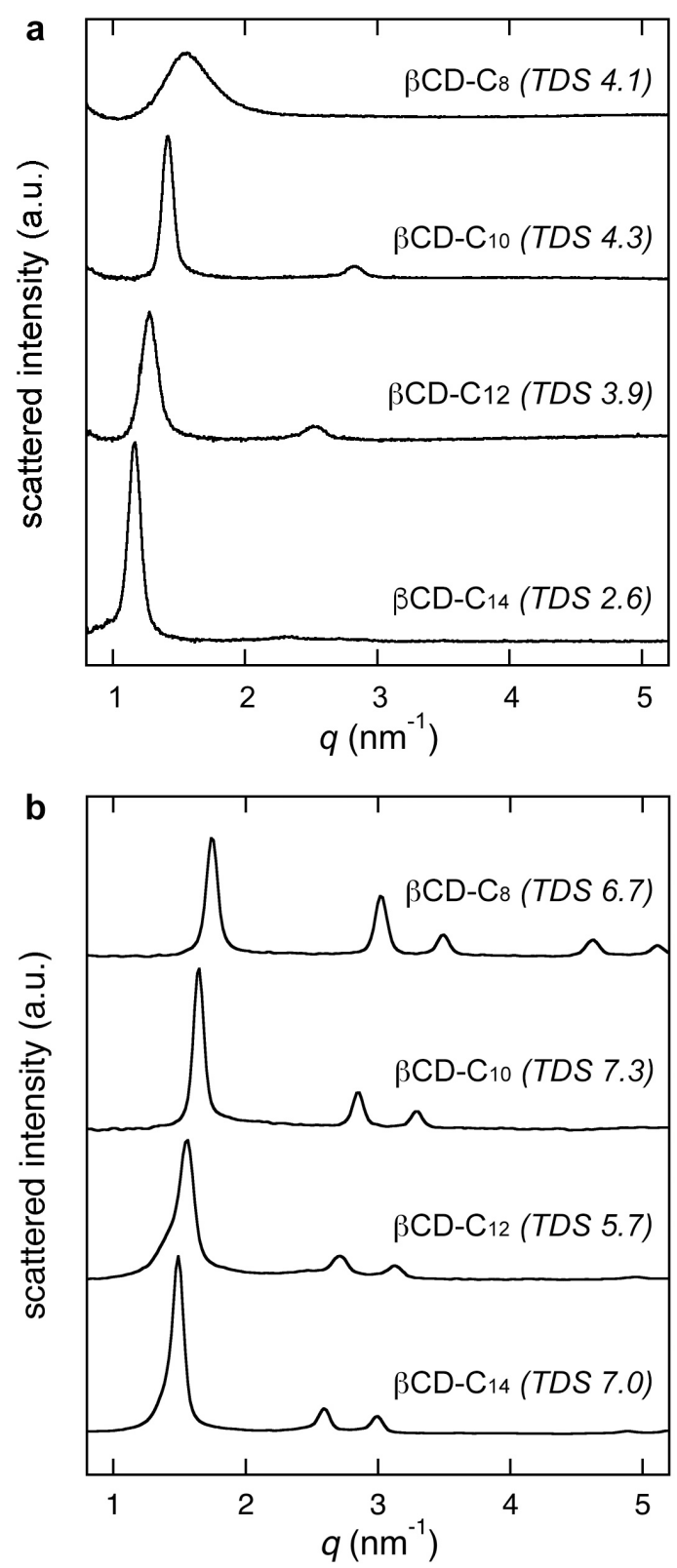

Figure 2. SAXS profiles of nanoparticle suspensions prepared from various $\beta C D-C_{n}$ derivatives: a) TDS $<5$ (the SAXS patterns were recorded on the laboratory setup); b) TDS $>5$ (the patterns were recorded on the synchrotron SAXS setup).

\section{RESULTS}

\subsection{Morphology and Ultrastructure of the Self-assembled Nanosystems}

As seen in Figure 2, the colloidal suspensions prepared by nanoprecipitation of the series of $\beta C D-C_{n}$ derivatives can be divided into two groups, according to their SAXS patterns. The profiles of the specimens formed from derivatives with TDS $<5$ contain one strong peak located at $q_{1}=1.55,1.42,1.28$ and $1.17 \mathrm{~nm}^{-1}$ for $n=8,10,12$ and 14 , respectively. An 
additional weaker peak can be seen at approximately $q_{2}=2 q_{1}$ in the case of $n=10,12$ and 14 . This suggests that these derivatives self-assembled into lamellar structures. TEM images of vitrified specimens suggest that the nanoparticles prepared from the $\beta C D-C_{10}$ and $\beta C D-C_{14}$ are spherical (Figures 3a and 3d, respectively). Higher magnification cryo-TEM images of the $\beta C D-C_{10}$ system clearly reveal a pattern of densely packed concentric fringes (Figure $3 \mathbf{b}$ ). Since we can assume that the particles are randomly oriented inside the embedding film of ice and since they all exhibit this concentric pattern, it is likely that the particles have an onionlike structure made of self-assembled layers. However, these layers, visualized as dark fringes, are not equidistant and the organization is better described as a dense packing of concentric bilayers (Figure 3c). While the bilayers seem to exist close to the core of the $\beta C D-C_{10}$ particles, the organization is less perfect in $\beta C D-C_{14}$ nanoparticles (Figure 3e) and the multilamellar structure is rarely seen over whole particles (Figure 3f). In particular, the particle core and, sometimes, part of the peripheral regions do not exhibit a multilamellar organization. No specific structure can be recognized in these disorganized regions.

For the four systems, the lamellar repeat was calculated from the SAXS profiles as $d_{\text {lam-SAXS }}=2 \pi / q_{1}=4.05,4.43,4.92$ and $5.39 \mathrm{~nm}$, for $n=8,10,12$ and 14 , respectively (Table 2). The lamellar repeat was also evaluated from the radius of the ring observed in the power spectra of cryo-TEM images of $\beta C D-C_{10}\left(d_{\text {lam-TEM }}=4.1 \mathrm{~nm}\right)$ and $\beta C D-\mathrm{C}_{14}$ $\left(d_{\text {lam-TEM }}=4.8 \mathrm{~nm}\right)$ nanoparticles (Supporting Information Figure S1). The values are in good agreement with those measured by SAXS. As will be commented in more details in the Discussion, $d_{\text {lam }}$ corresponds to the periodic spacing of molecular bilayers

Table 2. Structural parameters of the nanostructures obtained by self-organization of $\beta C D-C_{n}$ derivatives (lamellar repeat $d_{\text {lam }}$ for multilamellar organizations and unit cell parameter $a_{\text {hex }}$ for hexagonal structures) measured from SAXS data and cryo-TEM images. $n_{C}$ is the number of carbon atoms in the substituted alkyl chains and TDS the total degree of substitution of the derivative. n. d.: not determined.

\begin{tabular}{cccccc}
\hline$n_{C}$ & TDS & $d_{\text {lam }}$ SAXS $(\mathrm{nm})$ & $d_{\text {lam }}$ TEM $(\mathrm{nm})$ & $a_{\text {hex }}$ SAXS $(\mathrm{nm})$ & $a_{\text {hex }}$ TEM $(\mathrm{nm})$ \\
\hline 8 & 4.1 & 4.05 & n. d. & - & - \\
8 & 6.7 & - & - & 4.20 & 3.9 \\
10 & 4.3 & 4.43 & 4.1 & - & - \\
10 & 7.3 & - & - & 4.40 & 4.2 \\
12 & 3.9 & 4.92 & n. d. & - & - \\
12 & 5.7 & - & - & 4.67 & 4.5 \\
14 & 2.6 & 5.39 & 4.8 & - & - \\
14 & 7.0 & - & - & 4.90 & 4.8 \\
\hline
\end{tabular}



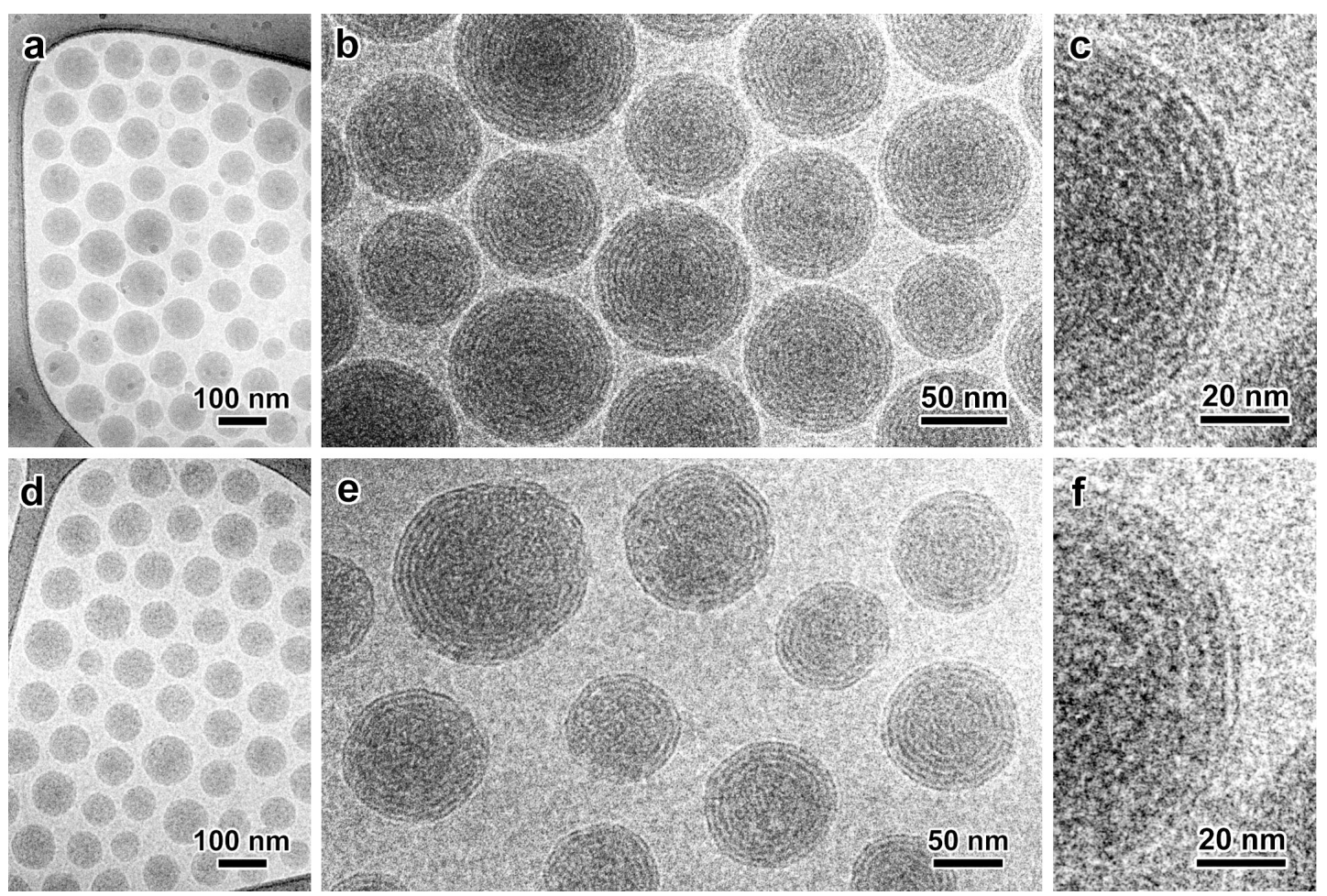

Figure 3. Cryo-TEM images of $\beta C D-C_{10}$ with $T D S=4.3(a-c)$, and $\beta C D-C_{14}$ with $\mathrm{TDS}=2.6(\mathrm{~d}-\mathrm{f})$ multilamellar nanoparticles embedded in vitreous ice.

The second group of specimens prepared from $\beta C D-C_{n}$ derivatives with TDS $>5$ exhibit a different structure and morphology. As seen in Figure 2b, the SAXS profiles contain three to five peaks with a series of $q_{\mathrm{i}} / q_{1}$ ratios $(1, \sqrt{3}, 2, \sqrt{7}, 3)$ that is indicative of a columnar hexagonal structure. The unit cell parameter was calculated from the SAXS profiles as $a_{\text {hex-SAXS }}=4.20,4.40,4.67$ and $4.90 \mathrm{~nm}$, for $n=8,10,12$ and 14, respectively (Table 2).

Most $\beta C D-C_{8}(T D S=6.7)$ particles have a rectangular shape (in projection), suggesting a barrel-like morphology (Figure 4a). Their length ranges from 50 to $150 \mathrm{~nm}$ and their width, from 30 to $50 \mathrm{~nm}$. Parallel lattice fringes can be seen in higher magnification cryo-TEM images. They are oriented along the long axis of some barrel-shaped particles (Figure 4b) while hexagonal patterns are more rarely observed on smaller facetted particles (Figures $4 \mathbf{b}$ and $\mathbf{4 c}$ ). The hexagonal symmetry was confirmed by calculating the power spectrum of the patterns (Supporting Information, Figure S2). 

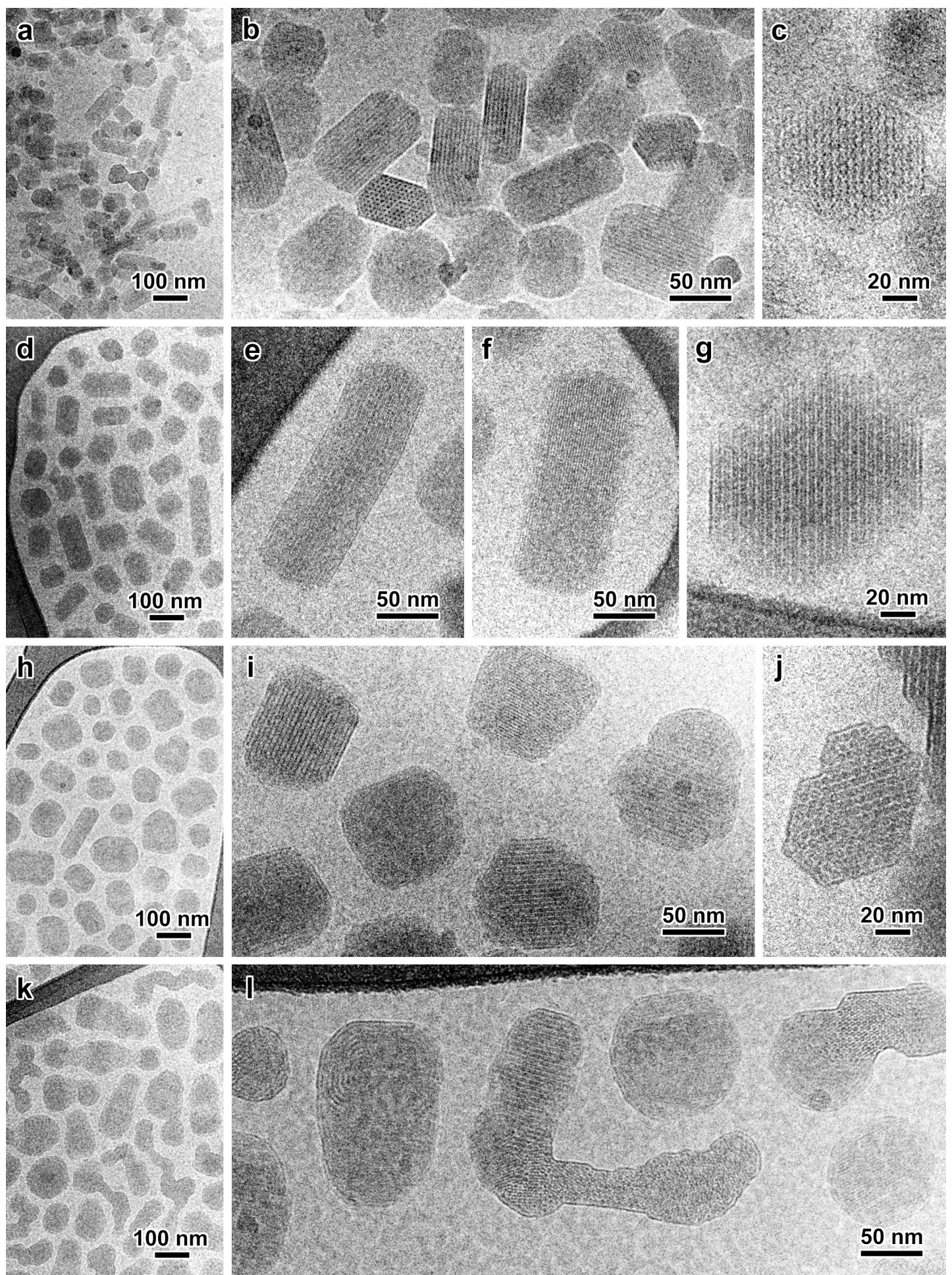

Figure 4. Cryo-TEM images of $\beta C D-C_{n}$ nanoparticles embedded in vitreous ice: a-c) $n=8$ $(\mathrm{TDS}=6.7) ; \mathrm{d}-\mathrm{g}) n=10(\mathrm{TDS}=7.3) ; \mathrm{h}-\mathrm{j}) n=12(\mathrm{TDS}=5.7) ; \mathrm{k}, \mathrm{l}) n=14(\mathrm{TDS}=7.0)$. 
The nanoparticles prepared from $\beta C D-\mathrm{C}_{10}$ with $\mathrm{TDS}=7.3$ exhibit a barrel shape, similar to that of the $\beta C D-C_{8}$ particles, with a 100-200 nm length and a 50-100 nm width (Figure 4d). At higher magnification, some of the particles display two types of lattice fringes, illustrated by the typical images in Figures $4 \mathbf{e}$ and $\mathbf{4 f}$. This is consistent with the supposed columnar hexagonal organization if we consider that both images in Figures $\mathbf{4 e}$ and $\mathbf{4 f}$ correspond to two projections of the hexagonal lattice, as will be explained in the Discussion. Figure 4g is a higher magnification image of a particle exhibiting the same set of dark lattice fringes as that in Figure 4e. One can see that the fringes are not equidistant and that the projected structure can be described by parallel pairs of dark fringes. The peak in the power spectrum (PS) of such an image thus corresponds to the repeat distance between pairs of fringes, not individual ones, as was the case for images of multilamellar nanospheres.

The particles from $\beta C D-C_{12}(T D S=5.7)$ are more compact, with a variety of shapes. Occasional barrel-like objects are observed (Figure 4h). Different sets of lattice fringes can be seen in higher magnification images. Inside a given particle, the fringes are mostly parallel but curved layers often occur at the edge or around some particles (Figure 4i). Hexagonal patterns are also occasionally observed on smaller facetted particles (Figure $\mathbf{4 j}$ ). The strongest SAXS peak exhibits a shoulder at $q \approx 1.42 \mathrm{~nm}^{-1}$ and a weak peak can also be detected at about $q \approx 2.46 \mathrm{~nm}^{-1}$. This may correspond to the presence of a minor second hexagonal phase but the signal is not strong enough to unequivocally conclude on its origin.

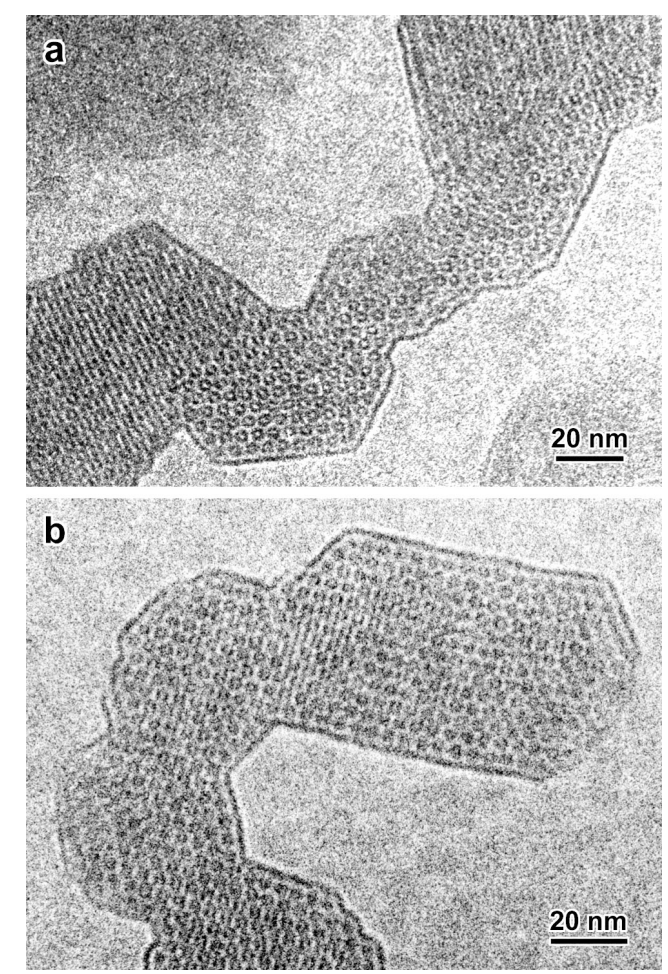

Figure 5. Higher magnification cryo-TEM images of facetted $\beta C D-C_{14}(T D S=7.0)$ nanoparticles. In some regions, the columns are perfectly aligned along the observation direction, allowing to clearly see the hexagonal organization. 
The particles prepared from $\beta C D-C_{14}$ with $\mathrm{TDS}=7.0$ exhibit a variety of shapes. In particular, a significant number of particles have a peculiar irregular and tortuous morphology (Figure 4k). At higher magnification, the lattice fringe patterns also seem to depend on the shape and orientation of the objects. Most interestingly, the tortuous particles exhibit a variety of patterns, suggesting that they are constituted of distinct regions with different orientations with respect to one another (Figure $\mathbf{4 j}$ ). This is illustrated by the images in Figure 5. Some regions of the particles exhibit parallel fringes whereas others contain sharp hexagonal patterns, the neighboring regions being separated by more or less clearly defined interfaces.

For the systems where cryo-TEM images of the axial projection were recorded, the hexagonal unit cell parameter was calculated form the Fourier transform: $a_{\text {hex TEM }}=3.9,4.5$ and $4.8 \mathrm{~nm}$ for $n=8,12$ and 14, respectively, in good agreement with the values determined by SAXS (Table 2). Since no image of the hexagonal arrangement was available for $\beta C D-C 10$, the cell parameter $\left(a_{\text {hex-TEM }}=4.5 \mathrm{~nm}\right)$ was calculated making an assumption on the nature of the lattice fringes observed in the longitudinal views that will be explained in the Discussion.

\subsection{Surface Properties of the $\beta C D-C_{n}$ Derivatives}

Compression isotherms at the air-water interface were recorded using the Langmuir film method. Initial experiments were carried out with pure chloroform as spreading solvent. Unfortunately, the $\beta C D-C_{n}$ derivatives with TDS $<5$ were not soluble in this solvent. Therefore, to obtain organic solutions without insoluble material, a chloroform/methanol mixture $(6: 4, \mathrm{v} / \mathrm{v})$ was selected as the spreading solvent. Surface pressure - molecular area $(\pi-A)$ isotherms were recorded, as shown in Supporting Information Figure S3a, except for $\beta C D-C_{8}(T D S=4.1)$ and $\beta C D-C_{12}(T D S=3.9)$ that were only partially soluble in this solvent mixture and, consequently, could not be spread for interfacial measurements. Large molecular areas at zero pressure corresponded to the gaseous state of the amphiphilic molecules. Then, for a molecular area around 1.75 and $2.90 \mathrm{~nm}^{2}$ for $\beta C D-C_{n}$ derivatives with TDS $<5$ and TDS $>5$, respectively, the increase in surface pressure indicated the beginning of the interaction between $\beta C D-C_{n}$ molecules at the air/water interface. All derivatives exhibited a steep increase in surface pressure when the molecular area decreased continuously up to the film break that was reached at a surface pressure between 42 and $48 \mathrm{mN} \mathrm{m}^{-1}$, depending on the derivative. The slope of the $\pi$ - $A$ isotherm provided information about the surface compressional modulus $C_{S}{ }^{-1}$ that indicates the physical state of the monolayer (Figure S3b). According to Davies and Rideal, ${ }^{43}$ surface compressional modulus $C_{s}^{-1}$ values around $\pi$ indicate an ideal state, while values in the range 12.5 to $50 \mathrm{mN} \mathrm{m}^{-1}$ correspond to the liquid expanded state. Values between 100 and $250 \mathrm{mN} \mathrm{m}^{-1}$ to the liquid condensed state and those above $1000 \mathrm{mN} \mathrm{m}^{-1}$ represent the solid state of the monolayer. 
Table 3. Characteristic values deduced from compression isotherms of $\beta C D-C_{n}$ monolayers at the air-water interface. $n_{C}$ is the number of carbon atoms in the substituted alkyl chains and TDS the total degree of substitution of the derivative.

\begin{tabular}{cccccc}
\hline$n_{C}$ & TDS & $A_{\text {mean }}\left(\mathrm{nm}^{2}\right)^{\mathrm{a}}$ & $C_{s}^{-1}\left(\mathrm{mN} \mathrm{m}^{-1}\right)^{\mathrm{b}}$ & $A_{\max }\left(\mathrm{nm}^{2}\right)^{\mathrm{c}}$ & $\pi_{\max }\left(\mathrm{mN} \mathrm{m}^{-1}\right)^{\mathrm{d}}$ \\
\hline 8 & 6.7 & $2.70 \pm 0.01$ & $145 \pm 1$ & $2.26 \pm 0.02$ & $26.9 \pm 1.5$ \\
10 & 4.3 & $1.64 \pm 0.02$ & $101 \pm 5$ & $1.23 \pm 0.04$ & $30.7 \pm 3.8$ \\
10 & 7.3 & $2.84 \pm 0.03$ & $187 \pm 4$ & $2.44 \pm 0.04$ & $28.9 \pm 1.7$ \\
12 & 5.7 & $2.47 \pm 0.04$ & $146 \pm 3$ & $2.02 \pm 0.04$ & $30.6 \pm 1.5$ \\
14 & 2.6 & $1.36 \pm 0.03$ & $112 \pm 6$ & $1.01 \pm 0.03$ & $31.7 \pm 2.6$ \\
14 & 7.0 & $2.55 \pm 0.02$ & $155 \pm 6$ & $2.09 \pm 0.04$ & $31.5 \pm 4.0$ \\
\hline
\end{tabular}

${ }^{a}$ Mean molecular area obtained by extrapolation to zero surface pressure.

b Maximum value of compression elastic modulus.

${ }^{\mathbf{c}}$ Molecular area obtained at the maximum value of compression elastic modulus.

${ }^{\text {d }}$ Surface pressure obtained at the maximum value of compression elastic modulus.

Table 3 summarizes the values of mean molecular areas, maximum surface compressional moduli, surface pressures and molecular areas at maximum values of surface compressional modulus for all the characterized $\beta C D-C_{n}$ derivatives. The maximum modulus, equivalent to a minimal compressibility, corresponds to pressures close to the biological equilibrium lateral pressure in the bilayer $\left(\pi_{\mathrm{e}} \approx 30 \mathrm{mN} \mathrm{m}^{-1}\right)$. Above this maximum, the compression modulus decreases, indicating the beginning of layer collapse. For all studied monolayers, the maximum surface compressional modulus $C_{s}^{-1}$ is characteristic of a liquid condensed state. Moreover, monolayers containing $\beta C D-C_{n}$ derivatives with TDS $<5$ have a lower molecular area and surface compressional modulus than monolayers containing derivatives with TDS $>5$, indicating that monolayers of derivatives with TDS $<5$ are more condensed but less organized than monolayers of derivatives with $\mathrm{TDS}>5 . \quad \beta C D-\mathrm{C}_{14} \quad(\mathrm{TDS}=2.6)$ and $\beta C D-\mathrm{C}_{10}$ (TDS $=7.3$ ), which are the two $\beta C D-C_{n}$ derivatives the most extreme in terms of degree of substitution, exhibited the lowest and the highest molecular areas, respectively, suggesting that TDS is the main factor that governs the molecular area. In contrast, no relationship was obtained for the maximum surface compressional modulus $C_{s}{ }^{-1}$. The two $\beta C D-\mathrm{C}_{10}$ derivatives $\left(\mathrm{TDS}=4.3\right.$ and 7.3) display the lowest and the highest maximum moduli, respectively. $\beta C D-C_{n}$ derivatives with TDS $<5$ have lower molecular areas than the native $\beta C D\left(1.86 \mathrm{~nm}^{2}\right.$ assuming an external radius of $0.77 \mathrm{~nm}$ for the secondary face of the macrocycle ${ }^{44}$ ), whereas $\beta C D-C_{n}$ derivatives with TDS $>5$ have higher molecular areas. The solubilization of the $\beta C D-C_{n}$ derivatives with TDS $<5$ in the aqueous subphase may lead to instable monolayers and material 
loss from the monolayer which would result in the shift toward lower molecular areas. Moreover, a re-orientation of the macrocycle at the air/water interface where the $\beta \mathrm{CD}$ cavity axis is tilted with respect to the interface is possible. ${ }^{45}$ For $\beta C D-C_{n}$ derivatives with TDS $>5$, a tilt of aliphatic chains is likely, resulting in a corolla-like conformation and a higher molecular area. ${ }^{46}$

\section{DISCUSSION}

\subsection{Classification of the Structures as a Function of TDS}

The eight $\beta C D-C_{n}$ amphiphilic derivatives studied during this work self-organized into particles by nanoprecipitation and all of them formed periodic ultrastructures that were successfully characterized by SAXS, and, for most of them, directly visualized by cryo-TEM. Indeed, our results expand from those previously published by Choisnard et $a l^{35}$ by adding higher resolution cryo-TEM images of several nanosystems as well as new complementary SAXS data. Typically, two different behaviors were observed. On the one hand, the $\beta C D-C_{n}$ derivatives with TDS $<5$ self-assembled into spherical nanoparticles exhibiting a multilamellar structure (Figure 3). On the other hand, the $\beta C D-C_{n}$ derivatives with TDS $>5$ formed barrel-like or facetted objects with a columnar inverse hexagonal mesophase (Figures 4 and 5). The unit cell parameter of the hexagonal lattices and the repeat distance of the lamellar structures are summarized in Table 2.

The results obtained from this specific series of $\beta C D-C_{n}$ derivatives show that their selforganized pattern does not depend on the length of the grafted alkyl chains but is mainly governed by TDS. The value of TDS $=5$ seems to conveniently define a limit between the two typical behaviors (lamellar or hexagonal organization). Choisnard et $a l^{41}$ have investigated the $\beta C D-C_{10}$ system in more details. A series of derivatives with different TDS were prepared and their average molecular weight was determined using complementary techniques, namely MALDI-TOF, ${ }^{1} \mathrm{H}$ nuclear magnetic resonance (NMR) spectroscopy and high-performance liquid chromatography (HPLC). A correlation between the morphology and ultrastructure of the nanoparticles (characterized by TEM and SAXS) and the molecular weight and TDS of the constituting $\beta C D-C_{10}$ was found. For TDS $<5$, the particles were multilamellar nanospheres whereas for TDS $>5$, they were barrel-like with a hexagonal structure. When TDS was around 5 , spherical and elongated particles coexisted and the SAXS profile contained peaks from both lamellar and hexagonal structures. Such a thorough study should be carried out for the different groups of $\beta C D-C_{n}$ derivatives with $n \neq 10$, in order to determine the TDS value separating the lamellar and hexagonal regimes with a better precision. 


\subsection{Description of the Different Supramolecular Organizations}

Our ultrastructural analysis relies on the complementarity of SAXS data and cryo-TEM images. The first technique provided information on the symmetry and repeat distances in the supramolecular assemblies while the second revealed specific projections of the structures. The results were combined to determine the molecular packing in the nanoparticles. In particular, whether the cryo-TEM lattice images are direct projections of the molecular arrangement depends on the defocus conditions. At an acceleration voltage of $80 \mathrm{kV}$ and with a typical defocus of the objective lens of -2.0 to $-3.0 \mu \mathrm{m}$, the contrast transfer function is such that the regions with the highest density and a repeat distance of around $4 \mathrm{~nm}$ in the lattice images are transmitted with a dark contrast (Supporting Information Figure S4) ${ }^{47}$ In the cryo-TEM images of the various structure, the contrast variation is maximum when the electron beam is perpendicular to the central axis of the molecules. As the electron density of the $\beta C D$ moiety is higher than that of the alkyl chains, due to the presence of several oxygen atoms, to which we can add the contribution of the oxygen atoms of the ester bonds, we can thus assume that, with our imaging conditions, the $\beta C D$ macrocycle generates a darker contrast in the images.

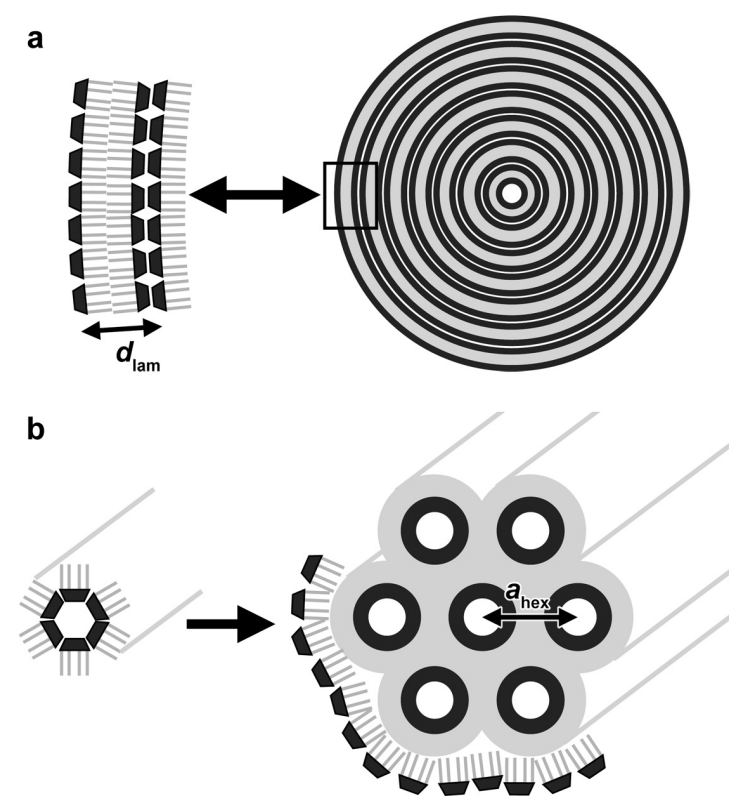

Figure 6. Tentative schemes of the supramolecular structures of $\beta C D-C_{n}$ nanoparticles: a) multilamellar structure made of concentric $\beta C D-C_{n}$ bilayers with a $d_{\text {lam }}$ spacing; b) inverse hexagonal structure made of $\beta C D-C_{n}$ columns whose lattice is defined by the $a_{\text {hex }}$ parameter. An extra single layer of $\beta C D-C_{n}$ surrounds the particle providing colloidal stability in water. In both schemes, the $\beta C D$ moieties are dark while the alkyl chains are light gray. 


\subsubsection{The Multibilayer Assemblies}

The simplest way to describe the multilamellar organization of $\beta C D-C_{n}$ derivatives with TDS $<5$ is to consider a dense packing of concentric bilayers, as previously proposed by Choisnard et $a l^{33}$ for nanoparticles of $\beta C D-C_{10}$ molecules, in agreement with the model of Zhang et al $^{48}$ and in analogy with what was observed in phospholipid systems ${ }^{49,50}$ and mixtures of phosphatidylcholine and glycerol dioleate. ${ }^{51}$ Sagalowicz et al observed self-assembled monolein/phospholipids nanoparticles whose cryo-TEM image exhibited patterns of concentric rings very similar to those observed on our $\beta C D-C_{10}$ system (Figure 3b).$^{52}$ By recording images of particles tilted at different angles, the authors demonstrated that the supramolecular organization was not multilamellar but rather corresponded to a hexagonal packing of circularly closed cylinders. As previously mentioned in section 3.1, we have ruled out this possibility owing to the random orientation of the particles in the ice film while they all presented the concentric pattern. The second reason is that the SAXS profile shown in Figure 2a contains only two peaks at $q_{1}$ and $2 q_{1}$ while an intermediate peak at $\sqrt{3} q_{1}$, which would have suggested a hexagonal structure, is absent. The same argument can be extended to the $\beta C D-C_{14}$ system.

As schematized in Figure 6a, the surface of the particle in contact with water would correspond to a layer of hydrophilic $\beta \mathrm{CD}$, thus ensuring a good colloidal stability. This layer appears as a dark fringe in Figures $3 \mathbf{c}$ (for $\beta C D-C_{10}$ ) and $\mathbf{3 f}$ (for $\beta C D-C_{14}$ ). The alternation of dark fringes would thus correspond to layers of $\beta C D$ moieties, either separated by a water layer or by two layers of alkyl chains.

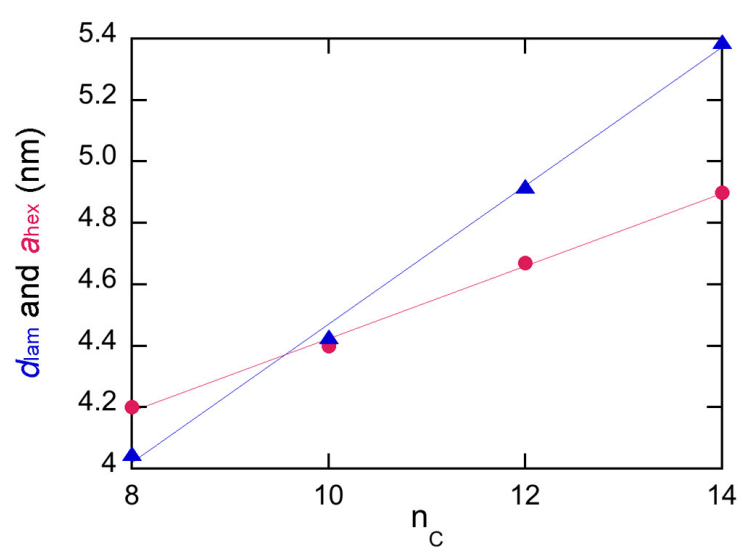

Figure 7. Variation of the lamellar spacing $d_{\text {lam }}$ (blue triangles) and hexagonal unit cell parameter $a_{h e x}$ (red disks) of the $\beta C D-C_{n}$ nanoparticulate systems with the number of carbon atoms $\left(n_{C}\right)$ in the grafted aliphatic chains. 
The variation of the lamellar repeat $d_{\text {lam }}$ with the number of carbon atoms in the grafted alkyl chains, plotted in Figure 7, is linear, in agreement with what was reported for the variation of the thickness of lipid bilayers. ${ }^{53,54}$ The repeat distance deduced by extrapolation to $n=0\left(d_{\text {lam }}=2.22 \mathrm{~nm}\right)$ provides an estimate of the thickness of the water layer separating the primary faces of the $\beta C D$ moieties. $d_{\text {lam }(n=0)}$ would correspond to the thickness of two $\beta C D$ moieties plus that of the water layer (Supporting Information Figure S5b). Assuming a $\beta C D$ height of $0.79 \mathrm{~nm}$, the thickness of the water layer would thus be $d_{w}=0.64 \mathrm{~nm}$, which is within the $0.5-1.5 \mathrm{~nm}$ range typically determined for lipid multibilayers. ${ }^{55-57}$

To a first approximation, if the $\beta C D$ moiety is parallel to the lamella plane and the alkyl chains perpendicular and extended, the lamellar repeat $d_{\text {lam-cal }}$ can be estimated by adding up the thickness of two $\beta C D-C_{n}$ molecules $\left(\beta C D^{44}+C_{n}\right.$ alkyl chain ${ }^{58}$ moieties $)$ and that of the water layer (Supporting Information Figure S5a). $d_{\text {lam-cal }}$ can then be compared to $d_{\text {lam-SAXS }}$ measured from SAXS profiles:

- $\quad \beta C D-C_{8}: \quad d_{\text {lam-cal }}=2 \times\left(0.79_{\mathrm{CD}}+0.94_{\mathrm{C} 8}\right)+0.64=4.10 \mathrm{~nm} \quad\left(d_{\text {lam-SAXS }}=4.05 \mathrm{~nm}\right)$

- $\beta C D-C_{10}: \quad d_{\text {lam-cal }}=2 \times\left(0.79_{\mathrm{CD}}+1.20_{\mathrm{C} 10}\right)+0.64=4.62 \mathrm{~nm} \quad\left(d_{\text {lam-SAXS }}=4.43 \mathrm{~nm}\right)$

- $\beta C D-C_{12}: \quad d_{\text {lam-cal }}=2 \times\left(0.79_{\mathrm{CD}}+1.46_{\mathrm{C} 12}\right)+0.64=5.14 \mathrm{~nm} \quad\left(d_{\text {lam-SAXS }}=4.92 \mathrm{~nm}\right)$

- $\beta C D-C_{14}: \quad d_{\text {lam-cal }}=2 \times\left(0.79_{\mathrm{CD}}+1.72_{\mathrm{C} 14}\right)+0.64=5.66 \mathrm{~nm} \quad\left(d_{\text {lam-SAXS }}=5.33 \mathrm{~nm}\right)$

In all cases, $d_{\text {lam-cal }}$ is higher than $d_{\text {lam-SAXs }}$ which supports the fact that the facing alkyl chains are not perfectly extended. Interdigitation may be involved to some extent, in particular since the $\beta C D$ moiety is not fully acetylated on $\mathrm{C} 2$ position, which creates some void that must be filled, resulting in a compaction of the bilayers.

In addition, if the alkyl chains were extended in the lamellar organization and noninterdigitating, the expected increase induced by four additional $\mathrm{CH}_{2}$ groups (two per facing alkyl chain) would be $0.54 \mathrm{~nm}$. The average increment calculated from the linear variation of $d_{\text {lam }}$ is about $0.44 \mathrm{~nm}$ for two $\mathrm{CH}_{2}$ group added in the alkyl chain. This lower value agrees with the previous observation. An increment of about $0.22 \mathrm{~nm}$ per added $\mathrm{CH}_{2}$ is consistent with the values reported for $\mathrm{L}_{\alpha}$ lipid bilayers $\left(0.17\right.$ and $0.19 \mathrm{~nm}$ by Lewis et al ${ }^{53}$ and Kučerka et al, ${ }^{54}$ respectively).

\subsubsection{The Inverse Hexagonal Assemblies}

We described the organization of $\beta C D-C_{n}$ molecules in the inverse hexagonal assemblies by making an analogy with the model proposed for various amphiphiles like, for instance, diglycerol monooleate / glycerol dioleate ${ }^{59}$ or aqueous glycerol monooleate / tricaprylin ${ }^{60}$ mixtures. In this so-called $\mathrm{H}_{\text {II }}$ phase, the $\beta C D-\mathrm{C}_{n}$ derivative would organize into columns with 
the alkyl substituents radiating outward (Figure 6b). As seen in Figure 7, the hexagonal parameter $a_{\mathrm{hex}}$, i.e. the distance between the centers of two neighboring columns, increases linearly with the number of carbon atoms in the alkyl chains. Cryo-TEM images of the axial projection of the structure brought additional information. Again, assuming that the darker contrast corresponds to the projection of the $\beta \mathrm{CD}$ moieties, the dark rings would be associated to the axial view of a $\beta C D$ column containing water molecules at the center. The extrapolation to $n=0$, corresponding to columns of $\beta C D$ moieties in close contact (Supporting Information Figure S6b) gives a distance $a_{\text {hex }(n=0)}=3.24 \mathrm{~nm}$. Assuming that the radius of the $\beta C D$ cylinders does not depend on the alkyl chain length, we can deduce that the external radius of the cylinders in close contact is $1.62 \mathrm{~nm}$ and that the radius of the median circle is about $1.22 \mathrm{~nm}$. This value is in good agreement with the corresponding radius directly estimated from cryoTEM images of the $\beta C D-C_{14}$ nanoparticles $\left(r_{\mathrm{col}}=1.2 \mathrm{~nm}\right)$.

Considering a simple model of non-interdigitating extended alkyl chains, the unit cell parameter can be calculated as (Supporting Information Figure S6a):

$$
a_{\text {hex-cal }}=2 r_{\mathrm{col}}+2 e_{\beta \mathrm{CD}-\mathrm{Cn}}-e_{\beta \mathrm{CD}}
$$

where $e_{\beta C D}$ is the thickness of the $\beta C D$ macrocycle $(0.79 \mathrm{~nm})$. We have only calculated $a_{\text {hex-cal }}$ for $\beta C D-C_{14}$ particles since the large number of images of the hexagonal structure in axial projection allowed to measure the hexagonal unit cell parameter and column diameter with a better precision. The experimental unit cell parameters measured from SAXS data and cryoTEM images $\left(a_{\text {hex-SAXS }}=4.90 \mathrm{~nm}\right.$ and $a_{\text {hex-TEM }}=4.8 \mathrm{~nm}$, respectively) both appear to be significantly smaller that the estimated value $\left(a_{\text {hex-cal }}=6.67 \mathrm{~nm}\right)$. The structure is thus more compact (Supporting Information Figure S6c).

The linear increase of $a_{\text {hex }}$ with the number of carbon atoms in the alkyl chains corresponds to an average increment of $0.24 \mathrm{~nm}$ when two $\mathrm{CH}_{2}$ groups are added in the alkyl chains (Figure 7). This value is significantly lower than that expected if alkyl chains of opposing molecules were facing each other while being extended and non-interdigitating.

According to models describing the hexagonal packing of amphiphiles, stretching and compression of alkyl chains should occur in order to fill the void regions between three neighboring columns, ${ }^{61,62}$ resulting in a net compaction of the structure. This means that, in our systems, the alkyl chains must either interdigitate, fold, tilt or a combination of the three, to accommodate the opposing constraints of column close-packing and steric repulsion. Moreover, the number and organization of $\beta C D-C_{n}$ molecules contained in the cross-section of one column is not known. Depending on this number, the molecules may be tilted with respect to the column axis. Analyzing the TEM images of freeze-fractured $\beta C D-C_{n}$ particles, 
Gulik et $a l^{63}$ proposed alternate molecular organizations based upon columns of $\beta C D-C_{n}$ dimers or trimers. However, since the reported hexagonal unit cell parameters were significantly smaller than our values, the authors proposed narrower columns.

Another feature of the particles with an inverse hexagonal ultrastructure revealed by cryo-TEM images is that, as suggested by the dark fringe systematically outlining individual particles (Figures $\mathbf{4 j}, \mathbf{4 l}$ and $\mathbf{5}$ ), a continuous layer of $\beta C D-C_{n}$ would cover the surface, with the hydrophilic primary face of the $\beta C D$ moiety in contact with water to maintain a good colloidal stability (Figure 6b). This observation is consistent with the mechanism previously proposed for the stabilization of various micellar structures. ${ }^{59-61}$
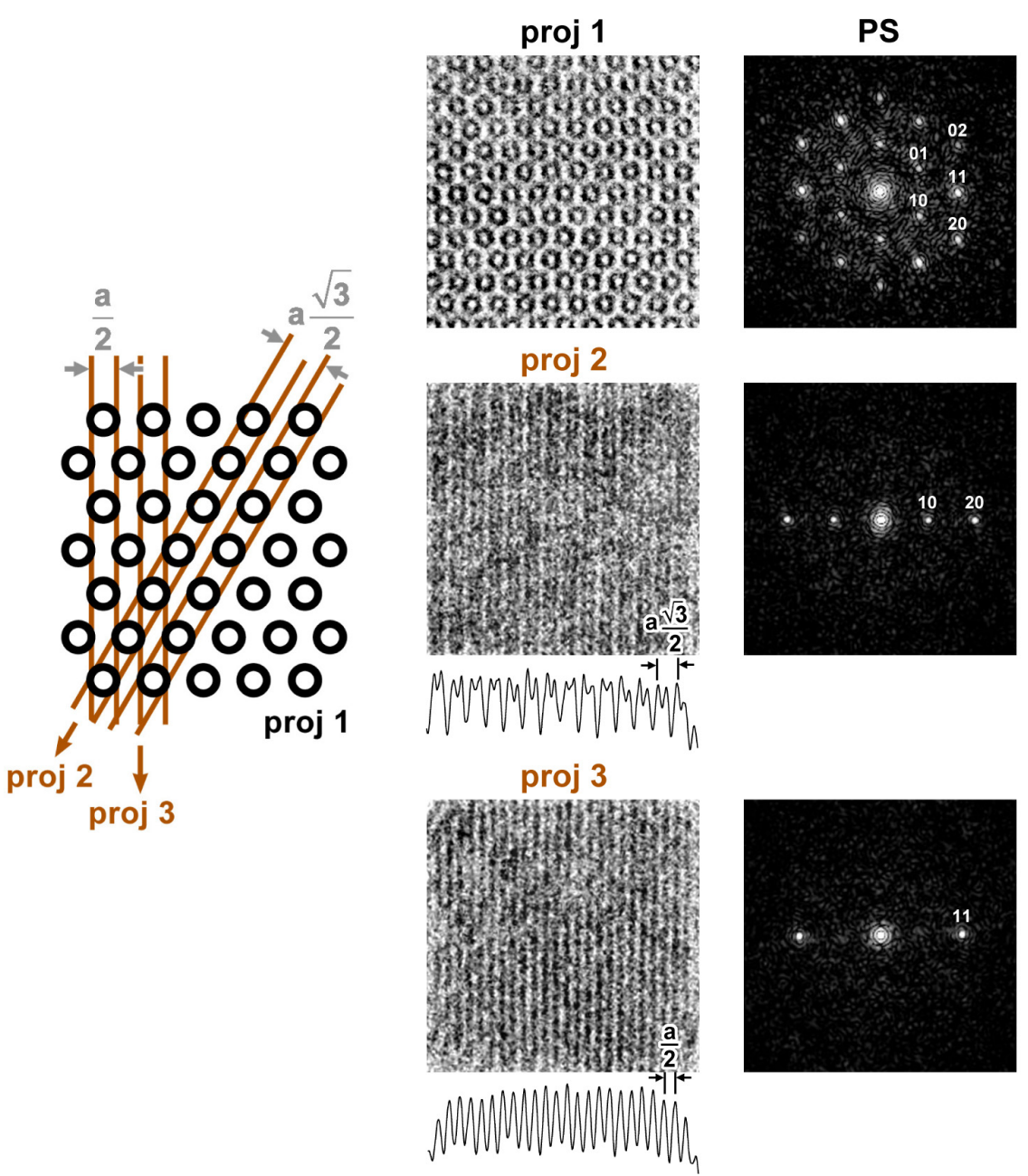

Figure 8. The 3 main projections of the inverse hexagonal structure observed in the cryo-TEM images $\left(50 \times 50 \mathrm{~nm}^{2}\right)$ and their corresponding power spectrum (PS). Projection 1 (proj 1) is the axial view along the columns. On the left, the scheme describes the spacings observed in longitudinal projections 2 and 3 (proj 2 and proj 3, respectively), assuming a hexagonal packing of $\beta C D-C_{n}$ columns. The red lines indicate the planes of highest density. A profile calculated by integrating the pixel intensity of the cryo-TEM images along the lattice direction is drawn under the images of projections 2 and 3 (the peaks correspond to the dark fringes). 
As shown in Figure 8, the axial model deduced from the cryo-TEM images (so-called "proj 1") allows to explain the fringe distribution in the longitudinal views of the barrel-like particles. As previously mentioned and illustrated, for instance, by Figures $4 \mathbf{e}, \mathbf{4 f}$ and $\mathbf{4 g}$, two patterns were observed ("proj 2" and "proj 3") yielding distinct intensity profiles (calculated along the lattice direction) and power spectra. Proj 2 corresponds to a view of the (10) planes, with a repeat distance of $a_{h e x} \frac{\sqrt{3}}{2}$, while proj 3 is a view of the (11) planes, with a repeat distance of $\frac{a_{h e x}}{2}$. The reflections in the PS of longitudinal proj 2 and proj 3 images can be recognized in the PS of the axial proj 1.

\subsection{Considerations on the Prediction of $\beta C D-C_{n}$ Nanoparticle Ultrastructure}

The "critical packing parameter" has been used to help describe the tendency of simple amphiphiles ${ }^{64,65}$ and in particular lipids ${ }^{66}$ to form specific ultrastructure. It is used to evaluate the global shape of a molecule, considering the cross-sectional area of the polar head and hydrophobic tail. It is defined as:

$$
C P P=\frac{v}{a \times l}
$$

where $v$ is the volume of the hydrophobic chain, $a$ is the cross-sectional area of the hydrophilic part and $l$ is the length of the hydrophobic chain. When $0.5<\mathrm{CPP}<1$, the molecule shape is an inverted truncated cone, promoting flexible bilayers and vesicles assemblies. When $\mathrm{CPP}=1$, the molecule is a cylinder and lamellar organizations are favored. When CPP $>1$, the molecule is conical and self-organizes into hexagonally-packed inverse columns. ${ }^{65,66} \mathrm{~A}$ revised CPP can be tentatively defined by taking into account the specific "multipod" geometry of the $\beta C D-C_{n}$ derivatives and, in particular, the presence of a central cavity:

$$
C P P_{\beta C D-C n}=\frac{T D S \times a_{a l k y l}}{a_{\beta C D}}
$$

$a_{\beta C D}$ is the area of the ring corresponding to the secondary face of the $\beta C D$ macrocycle $\left(1.54 \mathrm{~nm}^{2}\right)$ and $a_{\text {alkyl }}$ the cross-sectional area of one extended alkyl chain $\left(\sim 0.20 \mathrm{~nm}^{2}\right)$, which gives: $\mathrm{CPP}_{\beta \mathrm{CD}-\mathrm{Cn}}=0.13 \times$ TDS. The maximum value is obtained for the $\beta C D-\mathrm{C}_{10}$ derivative with TDS $=7.3(\mathrm{CPP}=0.95)$ and it is lower than 1. Consequently, the CPP approach cannot be directly transposed to our derivatives and in order to describe the effect of molecular shape on the type of self-assembled ultrastructure, conformational aspects are likely to be considered. For TDS $<5$, the conformation of the amphiphilic molecule must adapt in order to minimize the "void" resulting from the small number of substituents and the difference in molecular area. 
The alkyl chains may thus get closer to each other, which would confer to the molecule a inverted conical shape, inducing the formation of positively curved bilayers and the build-up of multibilayer organizations. As the surface compression analysis at the air-water interface showed that the molecular area was smaller than that of the $\beta C D$ macrocycle, it was also suggested that the $\beta C D$ moiety could rotate and not stay parallel to the plane of the lamellae.

For TDS $>5$, the substitution pattern may induce a steric hindrance of the alkyl chains that would push them outward, resulting in a conical shape that would promote negatively curved assemblies and the formation of inverse columns packed in a hexagonal fashion. This is consistent with the results from surface compression data that also suggested a corolla-like shape of these derivatives. The conformational effect of peracetylation on $\mathrm{C} 2$ and $\mathrm{C} 3$ positions, promoting steric hindrance, have been discussed by Zhang et al. ${ }^{48}$ Tchoreloff et $a l^{67}$ and Schalchli et $a l^{46}$ also mentioned an "opening" of the alkyl chains grafted on $\beta C D-C_{n}$ derivatives organized as monolayers at the air-water interface and on silicon wafers, respectively. To verify this assumption for molecules mostly acetylated at the $\mathrm{C} 2$ position, molecular dynamics should be carried out to investigate the conformational changes in the $\beta C D-C_{n}$ derivatives induced by different numbers of substituents. In particular, the role of the ester bond as a possible pivot point in the molecule should be examined since, depending on the TDS value, the van der Waals attraction or steric repulsion of the alkyl chains may induce distortions of the glucosyl units and thus modify the overall shape of the $\beta C D$ macrocycle. ${ }^{68}$

These considerations get even more complex if one considers that each fraction of $\beta C D-C_{n}$ derivative is not perfectly monodisperse and is actually a mixture of different regio-isomers with varying degrees of substitution. Only average values were considered in our study.

\section{CONCLUSION}

A series of $\beta C D-C_{n}(n=8,10,12$ and 14) amphiphilic derivatives with varying degree of substitution was nanoprecipitated into colloidal nanoparticles whose morphology and ultrastructure, characterized by combining data from cryo-TEM images and SAXS patterns, depended on the degree of substitution of the $\beta C D$ by the alkyl chains. Typically, the derivatives with TDS $<5$ formed nanospheres with a multilamellar organization whereas those with TDS $>5$ self-assembled into barrel-like $(n=8,10$ and 12) or more complex facetted $(n=14)$ particles with a columnar inverse hexagonal structure. Ultrastructural models were proposed based upon the analysis of the contrast distribution in cryo-TEM images and X-ray 
scattering data. Two distinct behaviors were also observed by analysis of surface compression data collected at the air-water interface.

Nanoparticulate ordered mesophases such as the so-called cubosomes or hexosomes ${ }^{69-72}$ have attracted a significant attention in the recent years due to their potential as drug delivery systems. ${ }^{73,74}$ The studied $\beta C D-C_{n}$ derivatives yielded hexosomes provided that their TDS was higher than 5 and, to our knowledge for the first time, we have shown high resolution images of the organization of the molecular columns inside the nanoparticles. Indeed, PEGylated particles prepared from $\beta C D-C_{10}($ TDS $=7.6)$ presenting a good in vivo colloidal stability ${ }^{75}$ and loaded with artemisinin have already been positively evaluated as potential longcirculating nanocarriers for injectable use. ${ }^{36}$ Our ultrastructural data should help drawing a better map of the distribution of the hydrophilic and hydrophobic regions in the particles in order to optimize the preparation of nanocarriers with a specific ultrastructure designed to control the entrapment and subsequent release of bioactive molecules.

While the present article mainly deals with descriptive aspects of the self-assembled structures of $\beta C D-C_{n}$ derivatives, computer modeling and molecular dynamics simulations should also be carried out in order to test the validity of the proposed supramolecular models, although the large number of molecules required to reliably describe the assemblies might be a limitation. In that case, the recent so-called coarse grain approaches may reveal helpful. ${ }^{76-78}$ In addition, molecular dynamics calculations can be used to study the formation of the supramolecular $\beta C D-C_{n}$ aggregates and particularly the initial building blocks. ${ }^{79}$

An important step to validate our tentative models will be to determine projected electron density maps. This can be done with two complementary approaches: i) by using molecular models from the coarse grain simulations, ii) by processing the SAXS data, a method that has been often used in the case of lipids and surfactant assemblies. ${ }^{80,81} \mathrm{In}$ both cases, the resulting maps will be compared to cryo-TEM images, taking into account the contrast transfer function of the microscope.

Finally, work is in progress to characterize the thermal stability of the various $\beta C D-C_{n}$ particles, as well as the morphological and structural modifications that hydrothermal treatments may promote. In addition, the nanosystems formed from $\beta C D-C_{14}$ with TDS $=7.0$ appeared to be highly original as they exhibited unusual tortuous and facetted shapes, as well as multidomain substructures. The specific geometry and topological defects of these particles will be described in detail in a separate article. 


\section{ACKNOWLEDGMENT}

The experiments were conducted with the financial support of Agence Nationale de la Recherche (grant number ANR-11-BS10-0007), ESRF (proposals 02-01-723 and 02-01-775) and Institut de Chimie Moléculaire de Grenoble (UAR 2607). The authors thank D. Levilly and C. Charrat (DPM) for the synthesis of amphiphilic cyclodextrins and nanoprecipitation experiments, respectively, as well as Y. Nishiyama and B. Jean (CERMAV) for their assistance during the data collection at ESRF, Y. Ogawa (CERMAV) for building the model of a $\beta C D-C_{10}$ molecule in Figure 1, and the NanoBio-ICMG platform (Grenoble) for granting access to the electron microscopy facility. We acknowledge support from LabEx ARCANE (grant number ANR-11-LABX-0003-01) and the Glyco@Alps program (Investissements d'Avenir grant number ANR-15-IDEX-02). F.-X. L. is grateful to J.-P. Michel (Institut Galien Paris-Sud) for granting access to the Langmuir trough and for fruitful discussions.

\section{REFERENCES}

(1) Tong, R.; Tang, L.; Cheng, J. Development and Application of Anticancer Nanomedicine. In "Nanostructure Science and Technology", 2012, chapter 3, pp. 31-46.

(2) Busseron, E.; Ruff, Y.; Moulin, E.; Giuseppone, N. Supramolecular Self-Assemblies as Functional Nanomaterials. Nanoscale 2013, 5, 7098-7140.

(3) Landesman-Milo, D.; Ramishetti, S.; Peer, D. Nanomedicine as an Emerging Platform for Metastatic Lung Cancer Therapy. Cancer Metastasis Rev. 2015, 34, 291-301.

(4) Lakshmanan, V.-K. Therapeutic Efficacy of Nanomedicines for Prostate Cancer: An Update. Investig. Clin. Urol. 2016, 57, 21-29.

(5) Felice, B.; Prabhakaran, M. P.; Rodríguez, A. P.; Ramakrishna, S. Drug Delivery Vehicles on a Nano-engineering Perspective. Mater. Sci. Eng. C 2014, 41, 178-195.

(6) Danhier, F.; Feron, O., Préat, V. To Exploit the Tumor Microenvironment: Passive and Active Tumor Targeting of Nanocarriers for Anti-Cancer Drug Delivery. J. Control. Release 2010, 148, 135-146.

(7) Mudshinge, S. R.; Deore, A. B.; Patil, S.; Bhalgat, C. M. Nanoparticles: Emerging Carriers for Drug Delivery. Saudi Pharm. J. 2011, 19, 129-141.

(8) Miladi, K.; Ibraheem, D.; Iqbal, M.; Sfar, S.; Fessi, H.; Elaissari, A. Particles from Preformed Polymers as Carriers for Drug Delivery. EXCLI Journal 2014, 13, 28-57

(9) He, Y.; Fu, P.; Shen, X.; Gao, H. Cyclodextrin-based Aggregates and Characterization by Microscopy. Micron 2008, 39, 495-516.

(10) Zhang, P.; Parrot-Lopez, M.; Tchoreloff, P.; Baszkin, A.; Ling, C.-C.; de Rango, C.; Coleman, A. W. Self-Organizing Systems Based on Amphiphilic Cyclodextrin Diesters. J. Phys. Org. Chem. 1992, 5, 518-528.

(11) Lakkakula, J. R.; Krause, R. W. M. A Vision for Cyclodextrin Nanoparticles in Drug Delivery Systems and Pharmaceutical Applications. Nanomedicine 2014, 9, 877-894.

(12) Biwer, A.; Antranikian, G.; Heinzle, E. Enzymatic Production of Cyclodextrin. Appl. Microbiol. Biotechnol. 2002, 59, 609-617. 
(13) Crini, G. A History of Cyclodextrins. Chem. Rev. 2014, 114, 10940-10975.

(14) Bilensoy, E.; Hincal, A. A. Recent Advances and Future Directions in Amphiphilic Cyclodextrin Nanoparticles. Expert Opin. Drug Deliv. 2009, 6, 1161-1173.

(15) Jabbari, A.; Sadeghian, H. Amphiphilic Cyclodextrins, Synthesis, Utilities and Application of Molecular Modeling in Their Design. In "Recent Advances in Novel Drug Carrier Systems", 2012, Sezer A. D. ed., InTech, chapter 12, pp 331-354.

(16) Yaméogo, J. B. G.; Gèze, A.; Choisnard, L.; Putaux, J.-L.; Semdé, R.; Wouessidjewe, D. Progress in Developing Amphiphilic Cyclodextrin-based Nanodevices for Drug Delivery. Curr. Topics Med. Chem. 2014, 14, 526-541.

(17) Bonnet, V.; Gervaise, C.; Djedaïni-Pilard, F.; Furlan, A.; Sarazin, C. Cyclodextrin Nanoassemblies: A Promising Tool for Drug Delivery. Drug Discov. Today 2015, 20, $1120-1126$.

(18) Nozaki, T.; Maeda, Y.; Ito, K.; Kitano, H. Cyclodextrins Modified with Polymer Chains Which Are Responsive to External Stimuli. Macromolecules 1996, 28, 522-524.

(19) Kauscher, U.; Stuart, M. C. A.; Drücker, P.; Galla, H.-J.; Ravoo, B. J. Incorporation of Amphiphilic Cyclodextrins into Liposomes as Artificial Receptor Units. Langmuir 2013, 29, 7377-7383.

(20) Quaglia, F.; Ostacolo, L.; Mazzaglia, A.; Villari, V.; Zaccaria, D.; Sciortino, M. T. The Intracellular Effects of Non-ionic Amphiphilic Cyclodextrin Nanoparticles in the Delivery of Anticancer Drugs. Biomaterials 2009, 30, 374-382.

(21) Erdoğar, N.; Esendağl1, G.; Nielsen, T. T.; Şen, M.; Öner, L.; Bilensoy, E. Design and Optimization of Novel Paclitaxel-loaded Folate-conjugated Amphiphilic Cyclodextrin Nanoparticles. Int. J. Pharm. 2016, 509, 375-390.

(22) Fessi, H.; Devissaguet, J.-P.; Puisieux, F.; Thies, C. Preparation Process for Disperse Colloidal Systems from a Substance in the Shape of Nanoparticles. Patent FR 2608988, 198607 01, 1988.

(23) Falvey, P.; Lim, C. W.; Darcy, R.; Revermann, T.; Karst, U.; Giesbers, M.; Marcelis, A. T. M.; Lazar, A.; Coleman, A. W.; Reinhoudt, D. N.; Ravoo, B. J. Bilayer Vesicles of Amphiphilic Cyclodextrins: Host Membranes That Recognize Guest Molecules. Chem. Eur. J. 2005, 11, 1171-1180.

(24) Roux, M.; Perly, B.; Djedaïni-Pilard, F. Self-assemblies of Amphiphilic Cyclodextrins. Eur. Biophys. J. 2007, 36, 861-867.

(25) Weisse, S.; Kalimouttou, S.; Lahiani-Skiba, M.; Djedaini-Pilard, F., Perly, B.; Skiba, M. Investigations on Topically Applied Vitamin A Loaded Amphiphilic Cyclodextrin Nanocapsules. J. Nanosci. Nanotechnol. 2009, 9, 640-645.

(26) Gèze, A.; Putaux, J.-L.; Choisnard, L.; Jehan, P.; Wouessidjewe, D. Long-term Shelf Stability of Original Amphiphilic -Cyclodextrin Nanosphere Suspensions Monitored by Dynamic Light Scattering and Cryo-transmission Electron Microscopy. J. Microencapsul. 2004, 21, 607-613.

(27) Sun, T.; Guo, Q.; Zhang, C.; Hao, J.; Xing, P.; Su, J.; Li, S.; Hao, A.; Liu, G. SelfAssembled Vesicles Prepared from Amphiphilic Cyclodextrins as Drug Carriers. Langmuir 2012, 28, 8625-8636.

(28) Shao, S.; Si, J.; Tang, J.; Sui, M.; Shen, Y. Jellyfish-Shaped Amphiphilic Dendrimers: Synthesis and Formation of Extremely Uniform Aggregates. Macromolecules 2014, 47, 916-921.

(29) Zhang, P.; Ling, C. C.; Coleman, A.W.; Parrot-Lopez, H.; Galons, H.; Formation of Amphiphilic Cyclodextrins via Hydrophobic Esterification at the Secondary Hydroxyl Face. Tetrahedron Lett. 1991, 32, 2769-2770.

(30) Skiba, M.; Duchêne, D.; Puisieux, F.; Wouessidjewe, D. Development of a New Colloidal Drug Carrier from Chemically-modified Cyclodextrins: Nanospheres and 
Influence of Physicochemical and Technological Factors on Particle Size. Int. J. Pharm. 1996, 129, 113-121.

(31) Gèze, A.; Choisnard, L.; Putaux, J.-L.; D. Wouessidjewe. Colloidal Systems Made of Biotransesterified , $\beta$ and -Cyclodextrins Grafted with C10 Alkyl Chains. Mat. Sci. Engineer. C 2009, 29, 458-462.

(32) Pedersen, N. R.; Kristensen, J. B.; Bauw, G.; Ravoo, B. J.; Darcy, R.; Larsena, K. L.; Pedersen, L. H. Thermolysin Catalyses the Synthesis of Cyclodextrin Esters in DMSO. Tetrahedron-Asymmetr. 2005, 16, 615-622.

(33) Choisnard, L.; Gèze, A.; Putaux, J.-L.; Wong, Y.-S.; Wouessidjewe, D. Novel Nanoparticles of $\beta$-Cyclodextrin Esters Obtained by Self-assembling of Biotransesterified -cyclodextrins. Biomacromolecules 2006, 7, 515-520.

(34) Skiba, M.; Wouessidjewe, D.; Puisieux, F.; Duchêne, D.; Gulik, A. Characterization of Amphiphilic $\beta$-Cyclodextrin Nanospheres. Int. J. Pharm. 1996, 142, 121-124.

(35) Choisnard, L.; Gèze, A.; Yaméogo, B. G. J.; Putaux, J.-L., Wouessidjewe, D. Miscellaneous Nanoaggregates Made of $\beta-C D$ Esters Synthesised by an Enzymatic Pathway. Int. J. Pharm. 2007, 344, 26-32.

(36) Yaméogo, J. B.; Gèze, A.; Choisnard, L.; Putaux, J.-L.; Gansané, A.; Sirima, S. B.; Semdé, R.; Wouessidjewe, D. Self-assembled Biotransesterified Cyclodextrins as Artemisinin Nanocarriers - I: Formulation, Lyoavailability and In Vitro Antimalarial Activity Assessment. Eur. J. Pharm. Biopharm. 2012, 80, 508-517.

(37) Lemos-Senna, E.; Wouessidjewe, D.; Lesieur, S.; Duchêne, D. Preparation of Amphiphilic Cyclodextrin Nanospheres using the Emulsification Solvent Evaporation Method. Influence of the Surfactant on Preparation and Hydrophobic Drug Loading. Int. J. Pharm. 1998, 170, 119-128.

(38) Memisoğlu-Bilensoy, E.; Hincal, A. A.; Bochot, A.; Trichard, L.; Duchêne, D. Amphiphilic Cyclodextrins and Microencapsulation. In "Microencapsulation Methods and Industrial Applications", Second Edition, Benita S. ed., Informa Healthcare 2005, chapter 9, pp. 269-295.

(39) Mendez-Ardoy, A.; Gómez-García, M.; Gèze, A.; Putaux, J.-L.; Wouessidjewe, D.; Ortiz Mellet, C.; Defaye, J.; García Fernández, J. M.; Benito, J. M. Monodisperse Nanoparticles from Self-assembled Amphiphilic Cyclodextrins: Modulable Tools for the Encapsulation and Controlled Release of Pharmaceuticals. Med. Chem. 2012, 8, 524-532.

(40) Yaméogo, J. B.; G.; Gèze, A.; Choisnard, L.; Putaux, J.-L.; Mazet, R.; Passirani, C.; Keramidas, M.; Coll, J.-L.; Lautram, N.; Béjaud, J.; Semdé, R.; Wouessidjewe, D. Self-assembled Biotransesterified Cyclodextrins as Potential Artemisinin Nanocarriers. II: In vitro Behavior Toward the Immune System and In Vivo Biodistribution Assessment of Unloaded Particles. Eur. J. Pharm. Biopharm. 2014, 88, 683-694.

(41) Choisnard, L.; Gèze, A.; Vanhaverbeke, C.; Yaméogo, J. B. G.; Putaux, J.-L.; Brasme, B.; Jullien, L.; Boullanger, S.; Elfakir, C.; Wouessidjewe, D. Physicochemical Characterization of $\alpha$-, $\beta$ - and $\gamma$-Cyclodextrins Bioesterified with Decanoate Chains, Used as Building Blocks of Colloidal Nanoparticles. Biomacromolecules 2011, 12, 3031-3038

(42) Challa, R.; Ahuja, A.; Ali, J.; Khar, R.K. Cyclodextrins in Drug Delivery: An Updated Review. AAPS PharmSciTech 2005, 6, E329-E357.

(43) Davies, J. T.; Rideal, E. K. Properties of Monolayers. In "Interfacial Phenomena", Academic Press, New York, 1961, chapter 5, pp. 217-281.

(44) Del Valle, E. M. M. Cyclodextrins and Their Uses: A Review. Process Biochem. 2004, 39, 1033-1046.

(45) Shtykov, S. N.; Klimov, B. N.; Gorin, D. A.; Pankin, K. E.; Gets'man, M. A.; Kurochkina, G. I.; Glazyrin, A. E.; Grachev, M. K. Properties of Monomolecular Layers 
and Langmuir-Blodgett Films on the Basis of $\beta$-Cyclodextrins with Various Numbers of Alkyl Chains. Russian J. Phys. Chem. A 2004, 78, 1632-1636.

(46) Schalchli, A.; Benattar, J. J.; Tchoreloff, P.; Zhang, P.; Coleman, A. W. Structure of a Monomolecular Layer of Amphiphilic Cyclodextrins. Langmuir 1993, 9, 1968-1970.

(47) Wang, L.; Bose, P. S.; Sigworth, F. J. Using Cryo-EM to Measure the Dipole Potential of a Lipid Membrane. Proc. Nat. Acad. Sci. 2006, 103, 18528-18533.

(48) Zhang, J.; Ma, P. X. Cyclodextrin-based Supramolecular Systems for Drug Delivery: Recent Progress and Future Perspective. Adv. Drug Deliv. Rev. 2013, 65, 1215-1233.

(49) Roux, D.; Chenevier, P.; Pott, T.; Navailles, L.; Regev, O.; Monval, O. M. Conception and Realization of a Non-Cationic Non-Viral DNA. Curr. Med. Chem. 2004, 11, 169-177.

(50) Lee, H.-Y.; Hashizaki, K.; Diehna, K.; Raghavan, S. R. Reverse Self-Assembly of Lipid Onions Induced by Gadolinium and Calcium Ions. Soft Matter 2013, 9, 200-207.

(51) Wadsäter, M.; Barauskas, J.; Nylander, T.; Tiberg, F. Formation of Highly Structured Cubic Micellar Lipid Nanoparticles of Soy Phosphatidylcholine and Glycerol Dioleate and Their Degradation by Triacylglycerol Lipase. ACS Appl. Mater. Interfaces 2014, 6, 7063-7069.

(52) Sagalowicz, L. ; Michel, M.; Adrian, M. ; Frossard, P. ; Rouvet, M.; Watzke, H. J.; Yaghmur, A.; De Campo, L.; Glatter, O.; Leser, M. E. Crystallography of Dispersed SelfAssembly Structures Studied by Cryo-TEM. J. Microsc. 2006, 221, 110-121.

(53) Lewis, B. A.; Engelman, D. M. Lipid Bilayer Thickness Varies Linearly with Acyl Chain Length in Fluid Phosphatidylcholine Vesicles. J. Mol. Biol. 1983, 166, 211-217.

(54) Kučerka, N.; Heberle, F. A.; Pan, J.; Katsaras, J. Structural Significance of Lipid Diversity as Studied by Small Angle Neutron and X-ray Scattering. Membranes 2015, 5, 454-472.

(55) Pfeiffer, W.; König, S.; Legrand, J.-F.; Bayerl, T.; Richter, D.; Sackmann, E. Neutron Spin Echo Study of Membrane Undulations in Lipid Multibilayers. Europhys. Lett. 1993, 23, 457-462.

(56) Nagle, J. F.; Tristam-Nagle, S. Structure of Lipid Bilayers. Biochim. Biophys. Acta 2000, 1469, 159-195.

(57) Rappolt, M.; Pabst, G.; Amenitsch, H.; Laggner, P. Salt-induced Phase Separation in the Liquid Crystalline Phase of Phosphatidylcholines. Colloid Surface A 2001, 183-185, 171-181.

(58) Lüttschwager, N. O. B.; Suhm, M. A. Stretching and folding of 2-nanometer hydrocarbon rods. Soft Matter 2014, 10, 4885-4901.

(59) Johnsson, M.; Lam, Y.; Barauskas, J.; Tiberg, F. Aqueous Phase Behavior and Dispersed Nanoparticles of Diglycerol Monooleate/Glycerol Dioleate Mixtures. Langmuir 2005, $21,5159-5165$.

(60) Amar-Yuli, I.; Wachtel, E.; Ben Shoshan, E.; Danino, D.; Aserin, A.; Garti, N. Hexosome and Hexagonal Phases Mediated by Hydration and Polymeric Stabilizer. Langmuir 2007, 23, 3637-3645.

(61) Shearman, G. C.; Ces, O.; Templer, R. H.; Seddon, J. M. Inverse Lyotropic Phases of Lipids and Membrane Curvature. J. Phys.: Condens. Matter 2006, 18, S1105-S1124.

(62) Mareš, T.; Daniel, M.; Perutková, S.; Perne, A.; Dolinar, G.; Iglič, A.; Rappolt, M.; KraljIglič, V. Role of Phospholipid Asymmetry in the Stability of Inverted Hexagonal Mesoscopic Phases. J. Phys. Chem. B 2008, 112, 16575-16584.

(63) Gulik, A.; Delacroix, H.; Wouessidjewe, D.; Skiba, M. Structural Properties of Several Amphiphile Cyclodextrins and some Related Nanospheres. An X-ray Scattering and Freeze-fracture Electron Microscopy Study. Langmuir 1998, 14, 1050-1057.

(64) Israelachvili, J. N. Soft and Biological Structures. In "Intermolecular and Surface Forces", third edition, 2011, chapter 20, pp 535-569. 
(65) Lombardo, D.; Kiselev, M. A.; Magazù, S.; Calandra, P. Amphiphiles Self-Assembly: Basic Concepts and Future Perspectives of Supramolecular Approaches. Adv. Cond. Matter Phys. 2015, 151683.

(66) Cullis, P. R.; Hope, M. J.; Tilcock, C. P. S. Lipid Polymorphism and the Roles of Lipids in Membranes. Chem. Phys. Lipids 1986, 40, 127-144.

(67) Tchoreloff, P. C.; Boissonnade, M. M.; Coleman, A. W.; Baszkin, A. Amphiphilic Monolayers of Insoluble Cyclodextrins at the Water/Air Interface. Surface Pressure and Surface Potential Studies. Langmuir 1995, 11, 191-196.

(68) Uccello-Barretta, G.; Balzano, F.; Cuzzola, A.; Menicagli, R.; Salvadori, P. NMR Detection of the Conformational Distortion Induced in Cyclodextrins by Introduction of Alkyl or Aromatic Substituents. Eur. J. Org. Chem. 2000, 449-453.

(69) Gustafsson, J.; Ljusberg-Wahren, H.; Almgren, M.; Larsson, K. Submicron Particles of Reversed Lipid Phases in Water Stabilized by a Nonionic Amphiphilic Polymer. Langmuir 1997, 13, 6964-6971.

(70) Barauskas, J.; Johnsson, M.; Tiberg, F. Self-Assembled Lipid Superstructures: Beyond Vesicles and Liposomes. Nano Lett. 2005, 5, 1615-1619.

(71) Boyd, B. J.; Whittaker, D. V.; Khoo, S., Davey, G. Hexosomes Formed from Glycerate Surfactants - Formulation as a Colloidal Carrier for Irinotecan. Int. J. Pharm. 2006, 318, 154-162.

(72) Sagalowicz, L.; Leser, M. E.; Watzke, H. J.; Michel, M. Monoglyceride Self-assembly Structures as Delivery Vehicles. Trends Food Sci. Technol. 2006, 17, 204-214.

(73) Phan, S.; Fong, W.-K.; Kirby, N.; Hanley, T.; Boyd, B. J. Evaluating the Link Between Self-assembled Mesophase Structure and Drug Release. Int. J. Pharm. 2011, 421, 176182.

(74) Chen, Y.; Ma, P.; Gui, S. Cubic and Hexagonal Liquid Crystals as Drug Delivery Systems. BioMed Res. Int. 2014, 815981.

(75) Gèze, A.; Choisnard, L.; Bacot, S.; Perret, P.; Charrat, C.; Levilly, D.; Lancelon-Pin, C.; Soubies, A.; Ghezzi, C.; Putaux, J.-L.; Riou, L.; Wouessidjewe, D. Biodistribution of Surface-decorated Biotransesterified $\quad \beta C D-N a n o p a r t i c l e s . ~ 17^{\text {th }}$ International Cyclodextrin Symposium (ICS17), 29-31 May, 2014, Saarbrücken, Germany.

(76) Patti, A.; Ramsch, R.; Marsa, C. S. Solvent-Free Model for Self-Assembling Amphiphilic Cyclodextrins. An Off-Lattice Monte Carlo Approach in Two Dimensions. J. Phys. Chem. B 2012, 116, 2687-2695.

(77) Khuntawee, W.; Wolschann, P.; Rungrotmongkol, T.; Wong-ekkabut, J.; Hannongbua, S. Molecular Dynamics Simulations of the Interaction of Beta Cyclodextrin with a Lipid Bilayer. J. Chem. Inf. Model. 2015, 55, 1894-1902.

(78) Sevink, G. J. A.; Charlaganov, M.; Fraaije, G. E. M. Coarse-Grained Hybrid Simulation of Liposomes. Soft Matter 2013, 9, 2816-2831.

(79) Raffaini, G.; Mazzaglia, A.; Ganazzoli, F. Aggregation Behaviour of Amphiphilic Cyclodextrins: The Nucleation Stage by Atomistic Molecular Dynamics Simulations. Beilstein J. Org. Chem. 2015, 11, 2459-2473.

(80) Rappolt, M.; Hickel, A.; Bringezu, F.; Lohner, K. Mechanism of the Lamellar/Inverse Hexagonal Phase Transition Examined by High Resolution X-Ray Diffraction. Biophys. J. 2003, 84, 3111-3122.

(81) Perutková, S.; Daniel, M.; Rappolt, M.; Pabst, G.; Dolinar, G.; Kralj-Iglič, V.; Iglič, A. Elastic Deformations in Hexagonal Phases Studied by Small-Angle X-ray Diffraction and Simulations. Phys. Chem. Chem. Phys. 2011, 13, 3100-3107. 


\section{Supporting Information}

Experimental section: Determination of the total degree of substitution (TDS, as defined in Challa et $\mathrm{al}^{42}$ ) from MALDI-MS data. For more details, see Choisnard et al. ${ }^{41}$

TDS is the average number of substituents per $\beta C D$ macrocycle. For $\beta C D-C_{n}$, the total degree of substitution obtained from MALDI-MS data (TDS ${ }_{\text {MALDI }}$ ) was computed according to the following equation:

$$
T D S_{M A L D I}=\frac{\left(M_{n M A L D I}^{\beta C D-C n}-M^{\beta C D}\right)}{\left(M^{\mathrm{CH}_{3}-\left(\mathrm{CH}_{2}\right)_{n-2}-\mathrm{CO}-}-M^{H}\right)}
$$

where $M_{n M A L D I}^{\beta C D-C n}$ is the average molar weight of the $\beta C D-C_{n}$ mixture, $M^{\beta C D}$ is the molar weight of the $\beta \mathrm{CD}, \mathrm{M}^{\mathrm{CH}_{3}-\left(\mathrm{CH}_{2}\right)_{n-2}-\mathrm{CO}-}$ the molar weight of ester residue and $M^{H}$ the molar mass of the hydrogen atom removed from the $\beta C D$ macrocycle during the transesterification reaction.

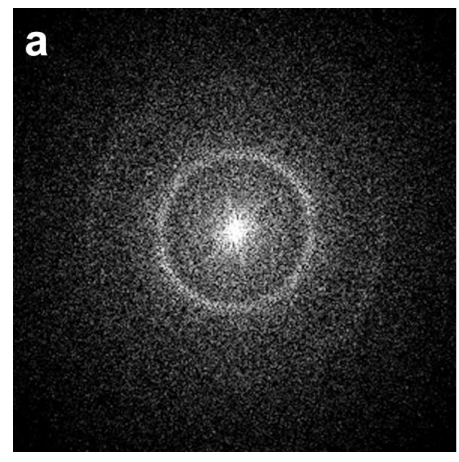

\section{b}

Figure S1. Power spectra calculated from cryo-TEM lattice images of two $\beta C D-C_{n}$ systems exhibiting a multilamellar structure: a) $n=10(\mathrm{TDS}=4.3)$; b) $n=14(\mathrm{TDS}=2.6)$. 


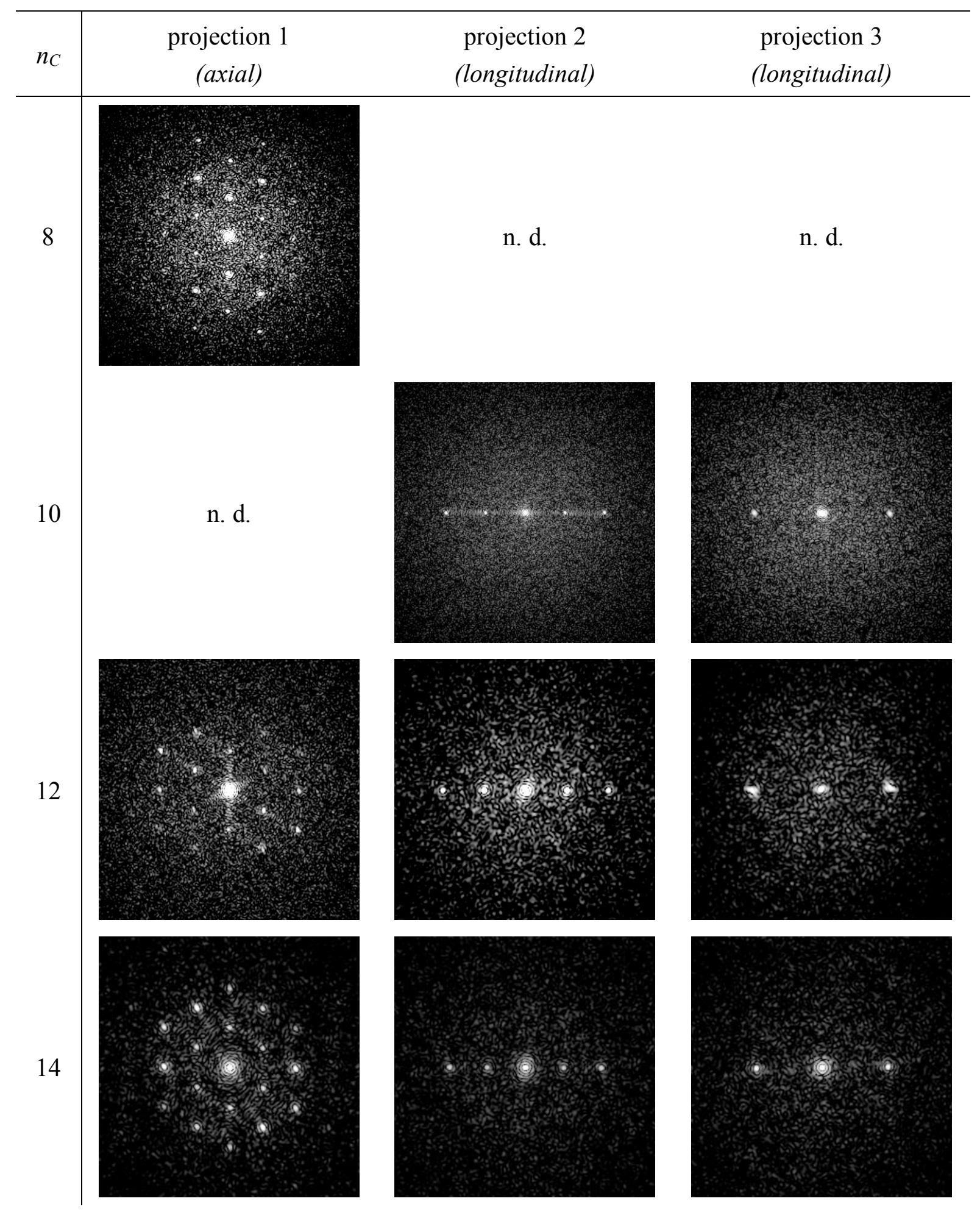

Figure S2. Power spectra calculated from cryo-TEM lattice images of $\beta C D-C_{n}$ particles containing a hexagonal structure: $n=8(\mathrm{TDS}=6.7) ; n=10(\mathrm{TDS}=7.3) ; n=12(\mathrm{TDS}=5.7)$; $n=14(\mathrm{TDS}=7.0)$. The left column (projection 1) shows the spectra calculated from structures in axial view, whereas the middle and right columns contain spectra calculated from two longitudinal views. For a description of each projection and spot indexing, see Figure 8. n. d.: not determined. 
a

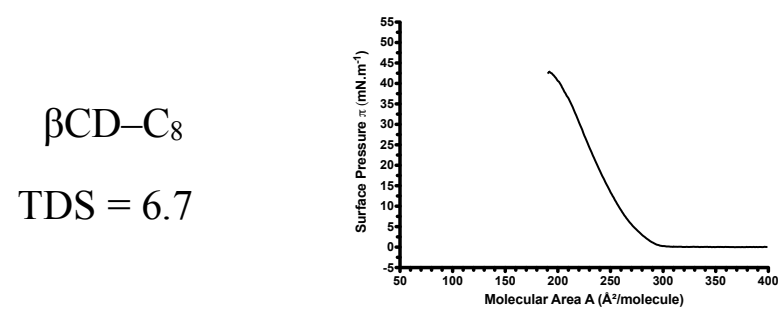

$\beta C D-C_{10}$

TDS $=4.3$

$\beta C D-\mathrm{C}_{10}$

TDS $=7.3$

$\beta \mathrm{CD}-\mathrm{C}_{12}$

$\mathrm{TDS}=5.7$

$\beta \mathrm{CD}-\mathrm{C}_{14}$

$\operatorname{TDS}=2.6$
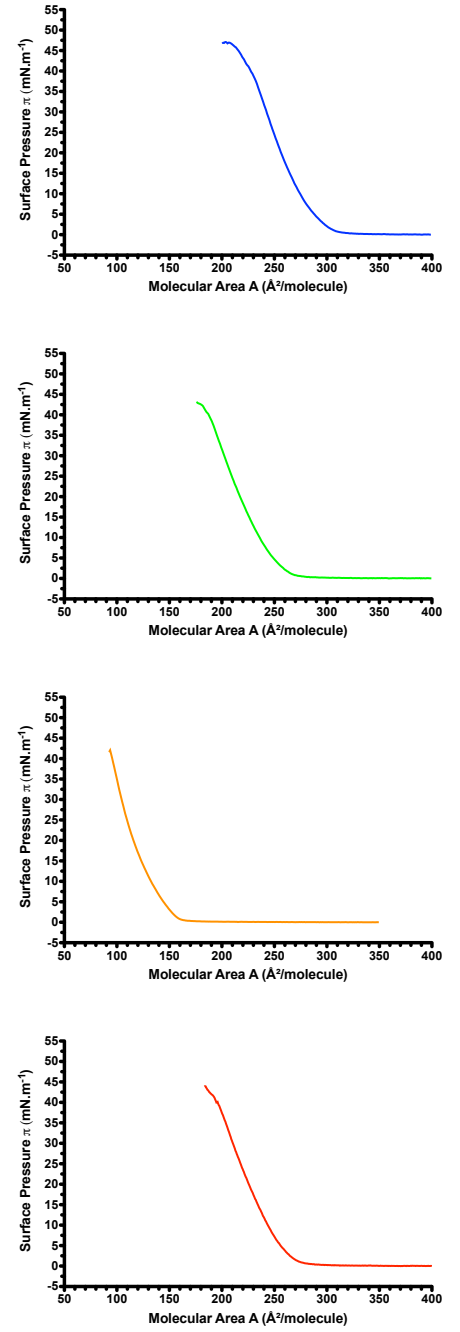

b
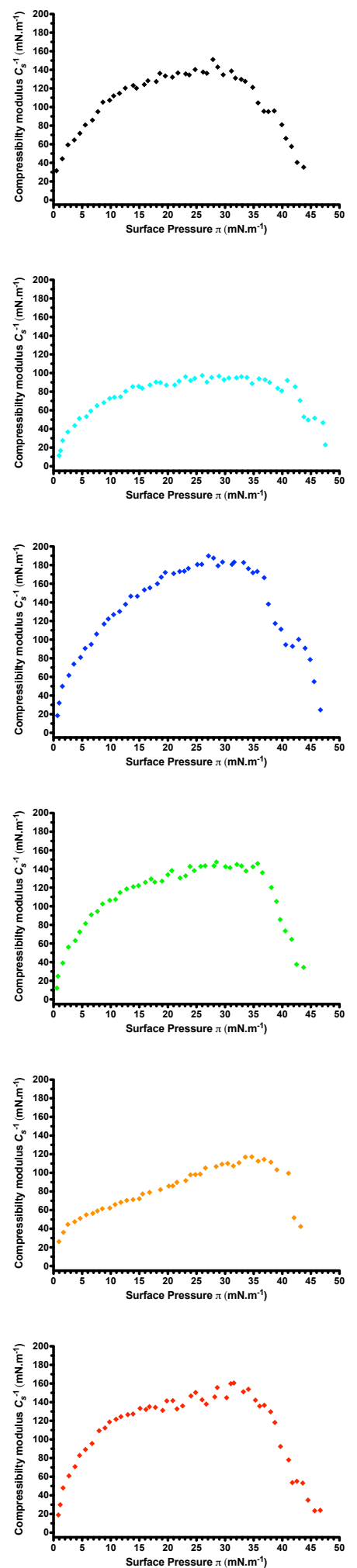

Figure S3. a) Surface pressure-molecular area compression $(\pi-A)$ isotherms of $\beta C D-C_{n}$ monolayers recorded at $24^{\circ} \mathrm{C}$ at the air-water interface; b) corresponding surface compressional modulus as a function of surface pressure. 


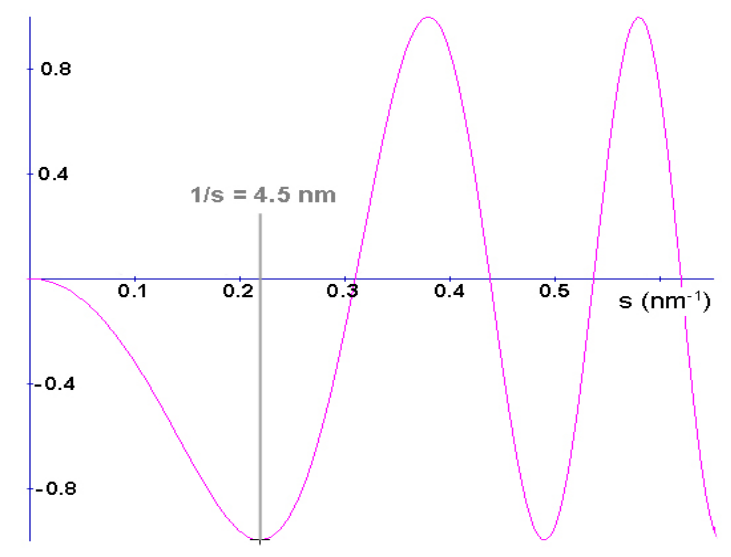

Figure S4. Contrast transfer function calculated for an acceleration voltage of $80 \mathrm{kV}$, a spherical aberration coefficient $\mathrm{Cs}$ of $2 \mathrm{~mm}$ and an objective lens defocus of $-2.5 \mu \mathrm{m}$. The envelope functions due to defocus and energy spread were not considered. At the selected defocus, the first transfer maximum corresponds to a distance of $4.5 \mathrm{~nm}$ in real space.

The contrast transfer function was calculated using the Java-based application at:

http://jiang.bio.purdue.edu/ctfsimu

Jiang, W.; Chiu, W. Web-based Simulation for Contrast Transfer Function and Envelope Functions. Microsc Microanal. 2001, 7, 329-334.

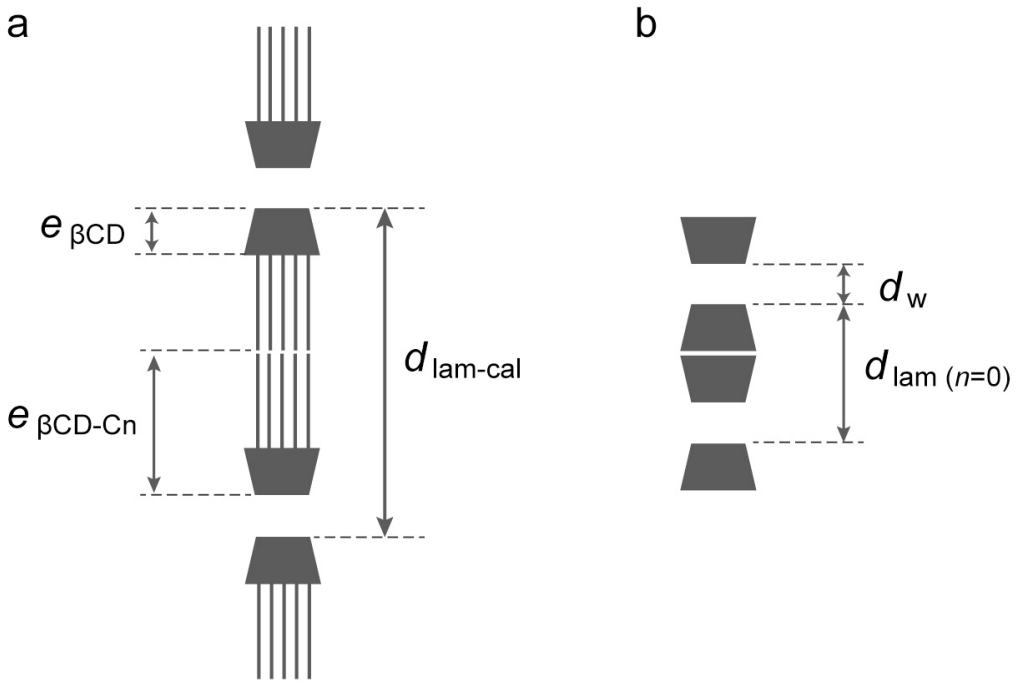

Figure S5. a) Position of neighboring $\beta C D-C_{n}$ columns in the multi-bilamellar structure, in the idealized case of extended aliphatic chains. $e_{\beta C D}$ is the thickness of the $\beta C D$ moiety and $e_{\beta C D}-\mathrm{Cn}$ is the thickness of the $\beta C D-C_{n}$ derivative assuming an extended chain conformation of the alkyl substituents. b) Position of the $\beta C D$ moieties when the number of carbons in the alkyl chain is extrapolated to $0 . d_{\mathrm{w}}$ is the thickness of the water layer between the primary faces of the $\beta C D$ moieties. 

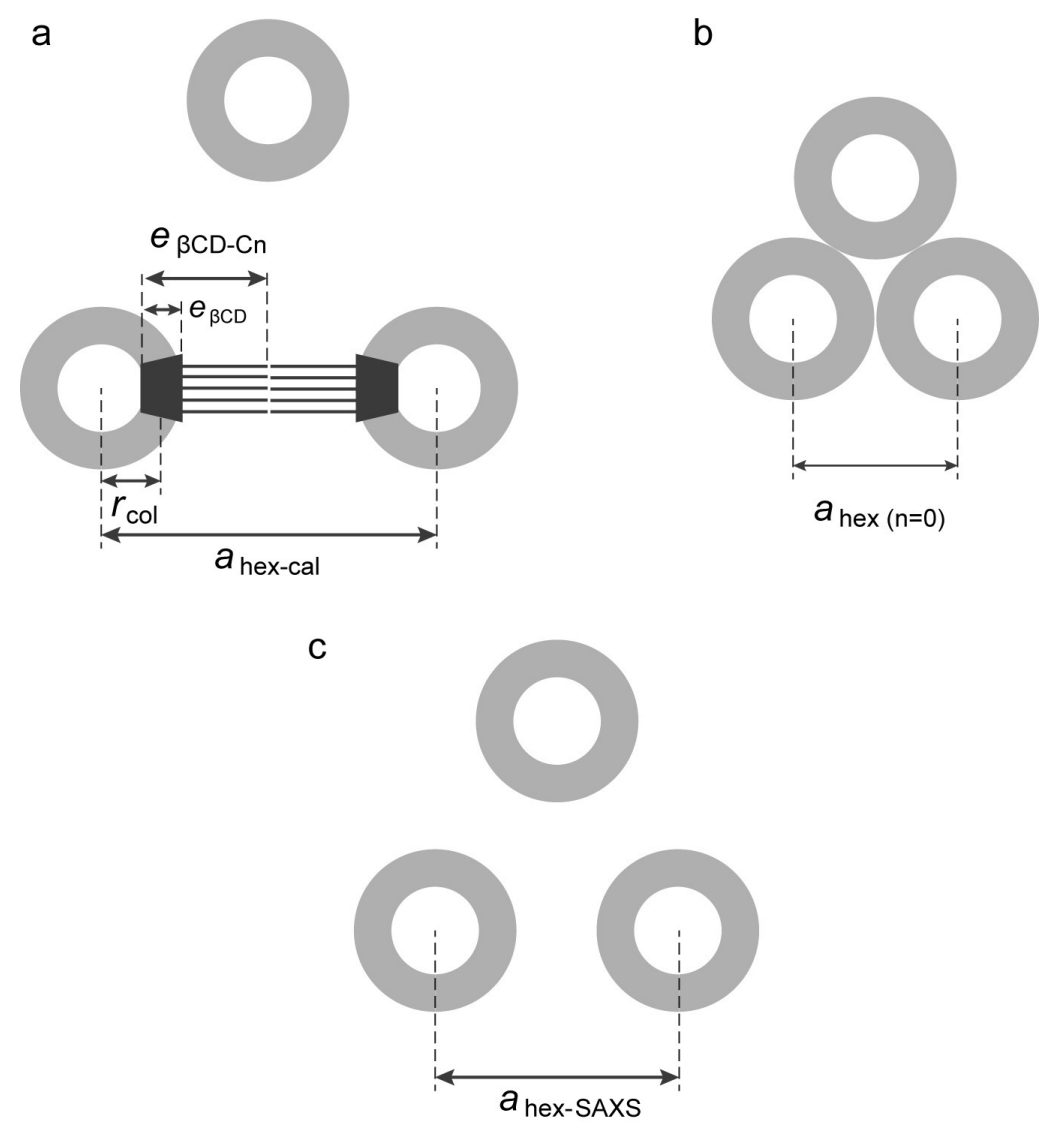

Figure S6. a) Position of three neighboring $\beta C D-C_{n}$ columns in the inverse hexagonal structure, in the idealized case of extended aliphatic chains. The gray rings correspond to the dark rings observed in the axial view of the hexagonal structure in cryo-TEM images such as that in Figure 5, and assumed to correspond to the projection of the $\beta C D$ moieties. For clarity, only two $\beta C D-C_{n}$ molecules were drawn. The column radius $r_{\text {col }}$ was taken as the median radius of the ring. $e_{\beta C D}$ is the thickness of the $\beta C D$ moiety and $e_{\beta C D}-\mathrm{Cn}$ is the thickness of the $\beta C D-\mathrm{C}_{\mathrm{n}}$ derivative assuming an extended alkyl chain conformation. b) Position of the $\beta C D$ columns when the number of carbons in the alkyl chain is extrapolated to 0. c) Experimental position of the columns based upon the cryo-TEM images. For $\beta C D-\mathrm{C}_{14}, a_{\text {hex-cal }}=6.67 \mathrm{~nm}$ and $a_{\text {hex-SAXs }}=$ $4.90 \mathrm{~nm})$. 